\title{
A Detailed Model for Simulation of Catchment Scale Subsurface Hydrologic Processes
}

\author{
Claudio Paniconi' and Eric F. Wood
}

\author{
Water Resources Program, Department of Civil Engineering and Operations Research, Princeton University, Princeton, New Jersey
}

\begin{abstract}
A catchment scale numerical model is developed based on the three-dimensional transient Richards equation describing fluid flow in variably saturated porous media. The model is designed to take advantage of digital elevation data bases and of information extracted from these data bases by topographic analysis. The practical application of the model is demonstrated in simulations of a small subcatchment of the Konza Prairie reserve near Manhattan. Kansas. In a preliminary investigation of computational issues related to model resolution, we obtain satisfactory numerical results using large aspect ratios, suggesting that horizontal grid dimensions may not be unreasonably constrained by the typically much smaller vertical length scale of a catchment and by vertical discretization requirements. Additional tests are needed to examine the effects of numerical constraints and parameter heterogeneity in determining acceptable grid aspect ratios. In other simulations we attempt to match the observed streamfiow response of the catchment, and we point out the small contribution of the streamflow component to the overall water balance of the catchment.
\end{abstract}

\section{INTRODUCTION}

The grid resolution required to obtain acceptable numerical solutions will be an important controlling factor in the computational feasibility of running large-scale catchment simulations. Discretization constraints can arise from physical or numerical considerations. Time steps can be numerically constrained in order to satisfy convergence, stability, or accuracy requirements. A physical constraint would typically be one which is imposed in order to capture the dynamics of a process of interest, for instance, a time step of the order of seconds or minutes if one is interested in the timing and magnitude of surface saturation and runoff responses during a heavy rainstorm. In the spatial domain one of the important constraints for a catchment scale subsurface model is connected to the aspect ratio of the numerical grid, which we define as the ratio of the horizontal mesh size $\Delta x$, $\Delta y$ to the vertical discretization $\Delta z$. The horizontal extent of a large catchment will typically be much greater than its vertical length scale (large surface area and comparatively thin soil zone), and often a very fine vertical resolution, especially near the surface, is needed to accurately simulate infiltration and evaporation processes. Numerical catchment simulations are therefore computationally feasible so long as we can use grids with a large aspect ratio. If we are constrained to adopt smaller aspect ratios (decreasing $\Delta x$, $\Delta y$ ) in order to overcome numerical difficulties, then the size of the problem (number of degrees of freedom) can quickly exceed the capacity of available computers.

In this paper we describe a physically based threedimensional finite element model for the simulation of subsurface hydrologic processes at the subcatchment and catchment scales, and we apply the model to a subcatchment of the Konza Prairie Research Natural Area near Manhattan, Kansas. The practical application of our model to actual catchments is demonstrated, and we investigate computa-

\footnotetext{
'Now at CRS4, Cagliari, Italy.

Copyright 1993 by the American Geophysical Union.
}

Paper number 92WR02333.

0043-1397/93/92WR-02333\$05.00 tional issues concerning the effects of model resolution (discretization, aggregation, and convergence constraints) on large-scale simulation of hydrologic processes.

One of the overriding problems in hydrology is the understanding of responses over the range of scales $O\left(10^{-1}\right)$ to $O\left(10^{4}\right) \mathrm{km}^{2}$ [Wood et al., 1988; Goodrich and Woothiser, 1991]. The low end of this range is roughly the size of a small subcatchment and marks a transition from point and hillslope scales, at which physically based hydrologic models are more easily tested and better understood, to catchment or basin scales. The high end corresponds to the horizontal grid scale used in general circulation models for global climate simulations, and a better understanding of hydrologic processes at this scale is required to improve the land surface boundary conditions for these models. The parameterization of hydrologic processes at large scales is made difficult by the high degree of nonlinearity and variability in catchment parameters and inputs, and thus conceptual or idealized models are often used at these scales. Physically based analytical or numerical models can be used to study the validity of simplifying assumptions in conceptual models. Some examples can be found in the works by Reeves and Miller [1975] (time compression approximation for partitioning rainfall into runoff and infiltration), Broadbridge and White [1987] (time to ponding), Gan and Burges [1990a, b] (catchment rainfall-runoff models), Shamsai and Narasimhan [1991] (Dupuit-Forchheimer assumption under seepage face conditions), Sloan and Moore [1984] and Stagnitti et al. [1986] (subsurface flow models), Wilcox et al. [1990] (runoff prediction models), and Troch et al. [1993] (catchment scale water balance models).

Other studies using physically based hillslope and catchment scale models include the early work of Freeze [1971, $1972 a, b]$, who used a three-dimensional finite difference variably saturated flow model coupled with a onedimensional channel flow model to reveal the importance of subsurface flow processes and parameter variability on watershed runoff response. Smith and Hebbert [1983] simplified the model used by Freeze and applied it to an experimental hillslope in Western Australia to investigate the effects of rainfall, soil properties, and hillslope geometry 

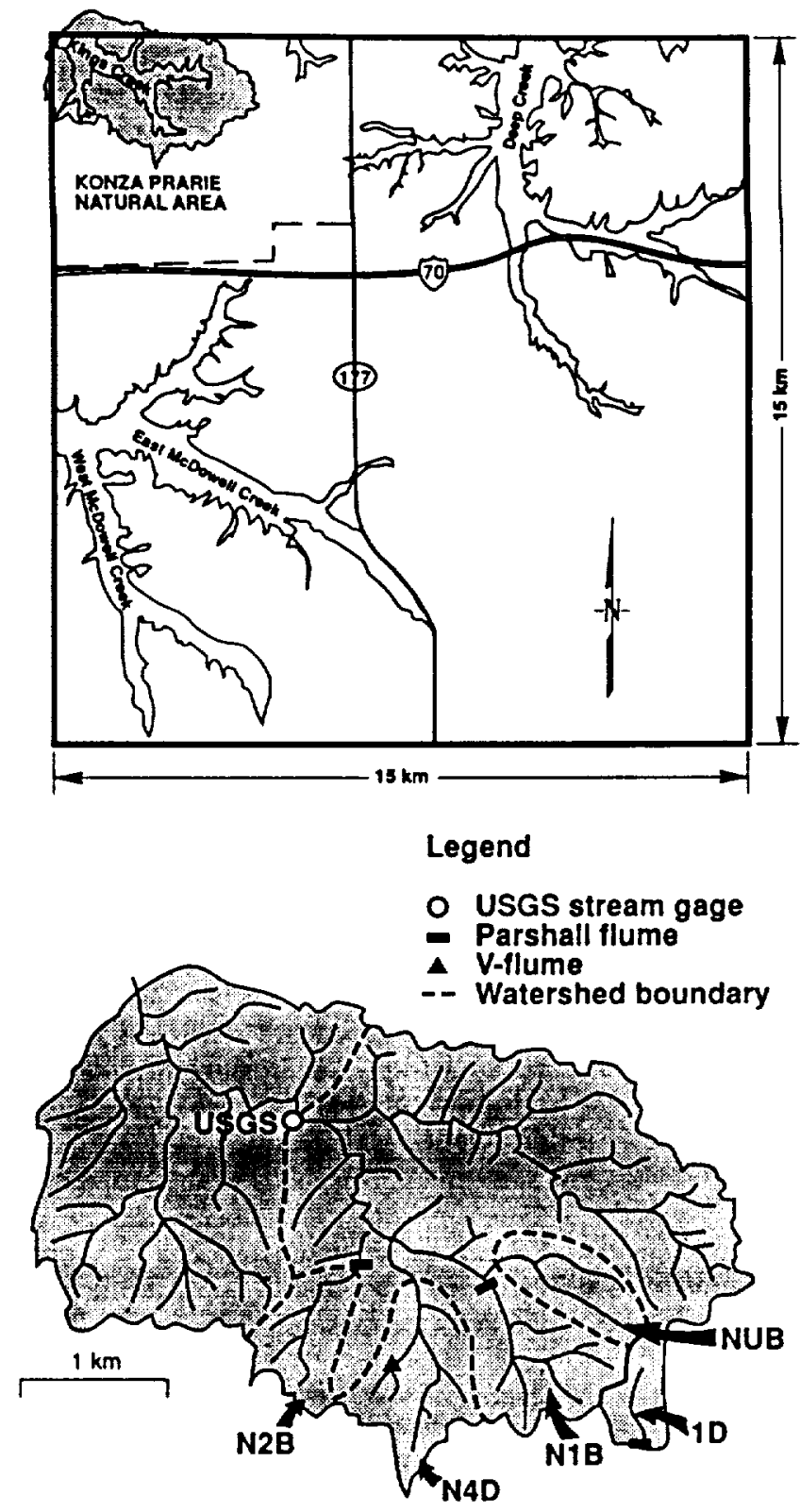

Fig. 1. Map showing location of the Konza Prairie Research Natural Area, the Kings Creek catchment, and the ID subcatchment.

on runoff. Loague and Freeze [1985] and Loague [1990] compared the performance of a simple linear regression model, a unit hydrograph model, and a quasi-physically based model in simulating rainfall-runoff response on small catchments. Beven [1977], Bathurst [1986], and Govindaraju and Kavvas [1991] coupled one- or two-dimensional subsurface flow models to physically based models of overland flow and channel flow. Binley et al. $[1989 a, b]$ used a threedimensional model of variably saturated flow to explore the effects of spatially variable hydraulic conductivity and the validity of using an equivalent or effective conductivity value.

The formulation of the numerical model presented here is consistent with one of the long-term objectives of our work, which is to simulate a large catchment such as the Kings Creek catchment shown in Figure 1, containing many dis- tinct subcatchment units and a complex stream network. In this paper we describe simulations of the $1 D$ subcatchment (Figures 1 and 2) located near the Kings Creek catchment (note that " $1 \mathrm{D}$ " is a site name and bears no relation to the dimensionality of the subcatchment). The primary input to the model is digital topographic data obtained from the U.S. Geological Survey. The original data are in regular grid form, with a resolution of $30 \times 30 \mathrm{~m}$, but can be readily interpolated or extrapolated to finer or coarser discretizations. An automated extraction algorithm [Band, 1986] is applied to the topographic data to produce a mapping of stream channels, catchment boundaries, and subcatchment partitions. Field observations and remotely sensed data are used for parameterization and calibration of the model. Atmospheric inputs to the model are specified as rainfall and evaporation boundary conditions, and the switching to and from atmosphere- and soil-controlled surface inputs is handled automatically.

The catchment simulation model is based on the threedimensional Richards equation describing fluid flow in variably saturated porous media. Of the many numerical issues associated with large-scale three-dimensional simulations, some which are specific to catchment subsurface flow modeling include, first, the nonlinearity of Richards's equation, and, at the interface between the saturated and unsaturated zones, possible discontinuities in the nonlinear coefficients and a change in type of the governing partial differential equation (parabolic to elliptic). The nonlinear system integrals require numerical evaluation or some other approximation technique, introducing additional error in the model. Moreover convergence of iterative schemes used to solve the nonlinear equation cannot be guaranteed, and the rate of convergence will depend upon many factors (such as the time step, which directly affects the quality of the initial solution estimate used in an iterative procedure). A second issue is naturally occurring spatial and temporal variability in soils, topography, vegetation, rainfall, and evaporation, requiring complex boundary conditions and a high degree of heterogeneity in the model parameterization. This can produce ill-conditioned system matrices and adversely affect the convergence behavior of linear and nonlinear iterative solvers. A third issue is the irregular geometry of catchments, resulting in sparse system matrices which are not regularly structured. A final issue to note is the large horizontal extent of a catchment compared to its vertical range and vertical discretization requirements, producing distorted elements.

A series of test simulations on three small hypothetical catchments was conducted to evaluate the performance of the numerical code [Paniconi, 1991]. The simulations involved alternating episodes of rainfall and evaporation, and generated significant amounts of discharge, infiltration, and saturation excess runoff. The tests included a comparison of lumped and distributed mass matrix versions of the code and a comparison of direct and iterative solvers for the linearized system of equations in the model. Various storage schemes for the system matrices and for the Jacobian coordinate transformation components were also examined.

In the next section we introduce the catchment simulation model and describe in detail the generation of the numerical grid and the representation of various hydrologic processes. This is followed by a description of the Konza Prairie ID catchment and observation data. The simulation model is then applied to a 17-day rainfall-interstorm sequence where 


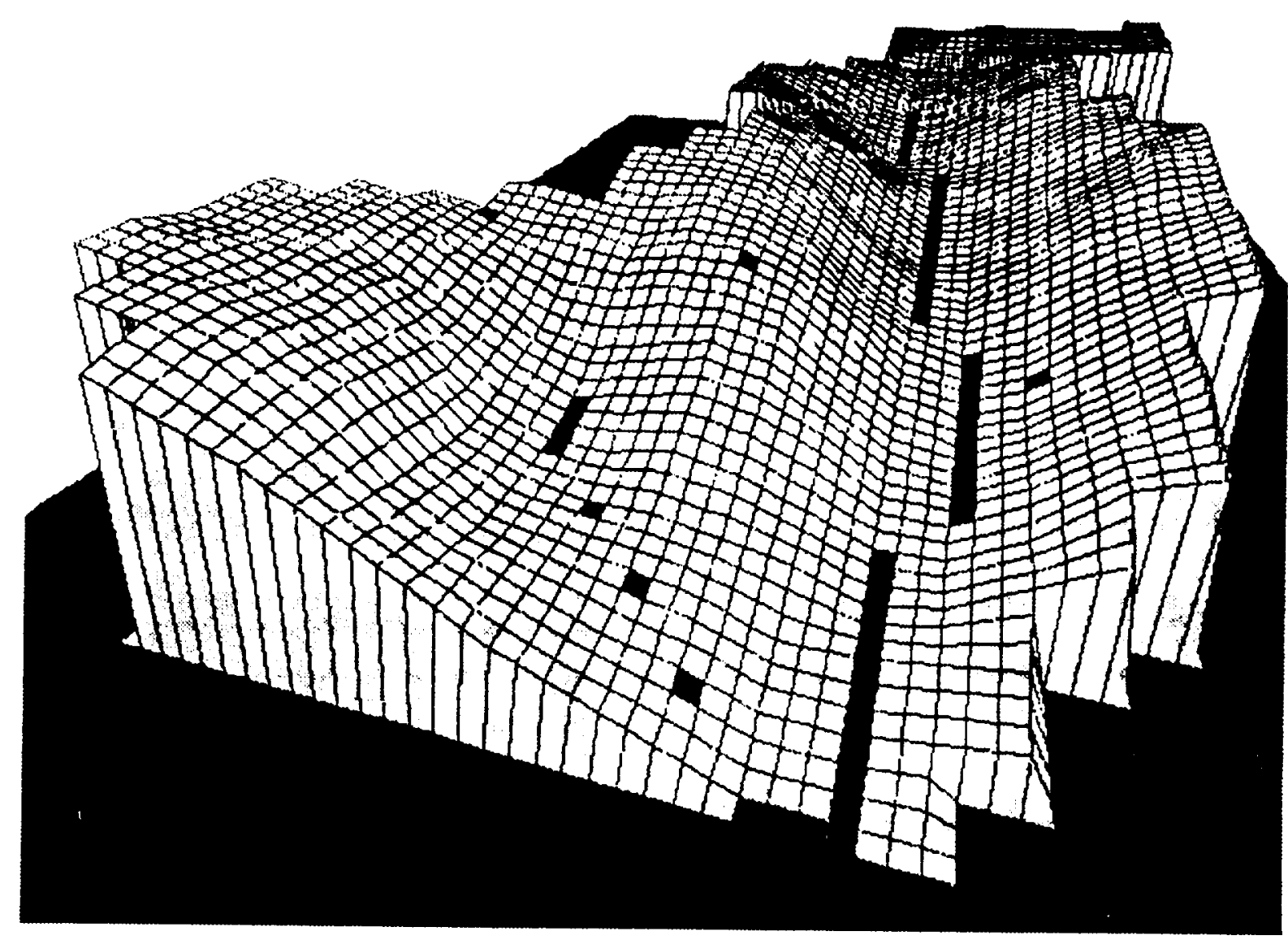

Fig. 2. Elevation image of subcatchment ID-10 (10 $10 \mathrm{~m}$ grid resolution) showing stream (solid pixels) and location of three surface nodes selected for vertical profile output (shaded pixels).

we discuss some calibration results. We use detailed and averaged rainfall rates for the 17-day simulation to illustrate temporal aggregation effects. Model resolution effects are discussed in more detail in section 4, where we use a 9-day interstorm simulation to examine aspect ratio and convergence constraints.

\section{Description of the Model}

\subsection{Assumptions and Limitations}

Basing our numerical model for flow in variably saturated porous media on Darcy's law and Richards's equation, we adopt the usual set of assumptions: Flow is laminar and isothermal, inertial forces and chemical gradients are neglected, and the air phase is continuous and at atmospheric pressure [e.g., Freeze and Cherry, 1979; Hillel, 1980a; Sposito, 1986]. In addition, we do not account for hysteresis, we assume that the porous medium is isotropic, and we consider only flow within the "soil matrix," neglecting flow through "macropores." Anisotropy can be easily incorporated with a generalization of the hydraulic conductivity term in the model equations. Since our model treats both precipitation and evaporation inputs, it will be important to consider hysteresis effects in future versions of the code. Mualem [1974], Parlange [1976], and Kool and Parker [1987] discuss some conceptual models of hysteresis for soil moisture characteristic equations.

Whereas anisotropy and hysteresis can be readily incorporated into our catchment simulation model, treating non- isothermal effects and macropore flow would require significant extensions or generalizations of the model. Several recent studies suggest that macropore flow (also described as bypass flow, channeling, pipe flow, or preferential flow) may contribute significantly to the transport of water through hillslopes and catchments [e.g., McDonnell, 1990; Pearce, 1990]. The term macropore generally refers to continuous pore structures which can exhibit nonequilibrium channeling flow, and it may not be appropriate to model this type of flow based on Darcy's law [Beven and Germann, 1982]. Twodomain models have been proposed for describing the flow and interactions in a soil matrix/macropore system, and kinematic wave models have also been introduced [e.g., Germann, 1990].

Subsurface heat transport and temperature-induced soil moisture flow are important not only for long-term simulations which need to account for seasonal changes in temperature, but also for short-term simulations when one considers the effects of diurnal fluctuations in solar and atmospheric radiation on near-surface soil moisture processes such as evaporation. Milly [1982] presents a physically based one-dimensional coupled moisture and heat flow model based on studies of nonisothermal flow in porous media by Philip and de Vries [1957] and de Vries [1958]. The model treats moisture flow in both the liquid and vapor phases and latent and sensible heat transport by conduction and advection.

The limitations described above pertain to the physics of flow processs within a porous medium. In a realistic basin 
scale model one must consider not only the coupling of processes in the saturated and unsaturated zones (soil matrix and macropores, air and liquid phases, heat and moisture flows), but also the coupling between subsurface, surface, and atmospheric hydrologic processes. Surface processes which affect and are affected by subsurface moisture and energy states include overland flow and streamflow [Eagleson, 1970; Freeze, 1974] and vegetation growth and transpiration [e.g., Federer, 1979]. The coupling with atmospheric processes takes us into the realm of large-scale water and energy balance models [e.g., Eagleson, 1978, 1979] which can become a component of general circulation models. Avissar and Verstraete [1990] discuss some of the difficulties involved in representing small-scale surface processes (such as albedo, stomatal response, momentum transfer, surface roughness, and soil moisture flow) in large-scale atmospheric models.

\subsection{Governing Equations and Numerical Procedures}

The three-dimensional Richards equation with pressure head $\psi$ as the dependent variable can be written as

$$
S(\psi) \frac{\partial \psi}{\partial t}=\nabla \cdot\left[K_{s} K_{r}(\psi) \nabla(\psi+z)\right]
$$

where $t$ is time, $z$ is the vertical coordinate, positive upward, and the hydraulic conductivity $K$ is expressed as a product of the conductivity at saturation, $K_{s}$, and the relative conductivity, $K_{r}$. We use an extension of the van Genuchten characteristic equations [van Genuchten and Nielsen, 1985] to describe the nonlinear dependencies of volumetric moisture content $\theta$, specific moisture capacity $S$, and relative hydraulic conductivity $K$, on pressure head [Paniconi et al., 19911:

$$
\begin{array}{cr}
\theta(\psi)=\theta_{r}+\left(\theta_{s}-\theta_{r}\right)[1+\beta]^{-m} & \psi \leq \psi_{0} \\
\theta(\psi)=\theta_{r}+\left(\theta_{s}-\theta_{r}\right)\left[1+\beta_{0}\right]^{-m}+S_{s}\left(\psi-\psi_{0}\right) \\
\psi \geq \\
S(\psi)=\frac{d \theta}{d \psi}=\frac{(n-1)\left(\theta_{s}-\theta_{r}\right)|\psi|^{n-1}}{\left|\psi_{s}\right|^{n}(1+\beta)^{m+1}} & \psi \leq \psi_{0} \\
S(\psi)=\frac{d \theta}{d \psi}=S_{s} & \psi \geq \psi_{0} \\
K_{r}(\psi)=(1+\beta)^{-5 m / 2}\left[(1+\beta)^{m}-\beta^{m}\right]^{2} & \psi \leq 0 \\
K_{r}(\psi)=1 & \psi \geq 0
\end{array}
$$$$
\psi \geq \psi_{0}
$$

where $\theta_{r}$ is the residual saturation, $\theta_{s}$ is the saturated moisture content, $\psi_{s}$ is the capillary or air entry pressure head value, $S_{s}$ is the specific storage, $m=1-1 / n, \beta=$ $\left(\psi / \psi_{s}\right)^{n}, \beta_{0}=\beta\left(\psi_{0}\right)=\left(\psi_{0} / \psi_{s}\right)^{n}, \psi_{0}$ is a continuity parameter, and $n$ can be interpreted as a pore size distribution index. The exponential relationship

$$
K_{s}=K_{s}(z)=K_{s,} \exp [-f(L-z)]
$$

is used to model vertical heterogeneity of saturated hydraulic conductivity [Beven, 1982, 1984], where $K_{s_{0}}$ is the saturated conductivity at the surface, $f$ is a fitting parameter, and $L$ is the elevation at the surface above the datum $z=0$.
To solve (1) numerically we use a finite element Galerkin discretization in space and a finite difference discretization of the time derivative term [e.g., Ames, 1977; Huyakorn and $P$ inder, 1983]. The problem domain is discretized into $M$ hexahedral elements and an approximating function is introduced:

$\psi(x, y, z, t) \approx \hat{\psi}(x, y, z, t)=\sum_{e=1}^{M} \hat{\psi}^{(e)}(x, y, z, t)$

In local coordinate space $(\xi, \eta, \zeta)$ the approximating function for each element $(e)$ is written as

$$
\begin{aligned}
& \hat{\psi}^{(e)}(\xi, \eta, \zeta, t)=\sum_{i=1}^{8} N_{i}^{(e)}(\xi, \eta, \zeta) \psi_{i}^{(e)}(t) \\
&=\left(\mathrm{N}^{(e)}(\xi, \eta, \zeta)\right)^{T} \Psi^{(e)}(t)
\end{aligned}
$$

where $\psi_{i}^{(e)}$ are undetermined nodal values of $\psi$ and $N_{i}^{(e)}$ are trilinear Lagrange basis functions which define, in local coordinate space, a cubic element with eight nodes at $( \pm 1$, $\pm 1, \pm 1)$. The basis functions have the general form $N_{i}(\xi, \eta$, $\zeta)=(1 \pm \xi)(1 \pm \eta)(1 \pm \emptyset / 8$. The finite element formulation used is isoparametric, with the mapping from local $(\xi, \eta, \zeta)$ to global $(x, y, z)$ coordinate space given by

$$
\begin{aligned}
(x, y, z)= & \left(\sum_{i=1}^{8} N_{i}(\xi, \eta, \zeta) x_{i},\right. \\
& \left.\sum_{i=1}^{8} N_{i}(\xi, \eta, \zeta) y_{i}, \sum_{i=1}^{8} N_{i}(\xi, \eta, \zeta) z_{i}\right)
\end{aligned}
$$

where $\left(x_{i}, y_{i}, z_{i}\right), i=1, \cdots, 8$ are the global coordinates of the eight corner nodes of element $(e)$.

The finite element spatial discretization yields the system of ordinary differential equations

$$
\mathbf{A}(\boldsymbol{\Psi}) \Psi+\mathbf{F}(\boldsymbol{\Psi}) \frac{d \Psi}{d t}=\mathbf{q}(t)-\mathbf{b}(\boldsymbol{\Psi})
$$

where $\Psi$ is the vector of undetermined coefficients representing the value of pressure head at each node. The system components for each element $(e)$ are

$$
\begin{aligned}
\mathbf{A}^{(e)}=\iiint_{\Omega^{(e)}} K_{s}^{(e)} K_{r}\left(\hat{\psi}^{(e)}\right)\left[\mathbf{N}_{, x}^{(e)}\left(\mathbf{N}_{, x}^{(e)}\right)^{T}\right. \\
\left.+\mathbf{N}_{, y}^{(e)}\left(\mathbf{N}_{, y}^{(e)}\right)^{T}+\mathbf{N}_{, x}^{(e)}\left(\mathbf{N}_{, z}^{(e)}\right)^{T}\right] d \Omega^{(e)} \\
\mathbf{b}^{(e)}=\iiint_{\Omega^{(e)}} K_{s}^{(e)} K_{r}\left(\hat{\psi}^{(e)}\right) \mathbf{N}_{, x}^{(e)} d \Omega^{(e)} \\
\mathbf{F}^{(e)}=\iiint_{\Omega^{(e)}} S\left(\hat{\psi}^{(e)}\right) \mathbf{N}^{(e)}\left(\mathbf{N}^{(e)}\right)^{T} d \Omega^{(e)} \\
\mathbf{q}^{(e)}=\iint_{\Gamma_{N}^{(e)}} q_{\Gamma_{N}^{(e)} \mathbf{N}^{(e)} d \Gamma_{N}^{(e)}}
\end{aligned}
$$


where $q_{\Gamma_{N}^{+e}}$ is the specified Darcy flux on the natural boundary $\Gamma_{N}^{(e)}$. We use the notation $\mathbf{N}_{, x}$ to denote differentiation with respect to $x$, and $N^{T}$ to denote the transpose of $N$. A lumped form of the mass matrix $F^{(e)}$ is used:

$$
\mathbf{F}^{(e)}=\iiint_{\Omega^{(e)}} S\left(\hat{\psi}^{(e)}\right) \mathbf{N}^{(e)} d \Omega^{(e)}
$$

where now $\mathbf{N}^{(e)}$ is taken to be a diagonal matrix rather than a vector.

The system integrals are nonlinear and must be evaluated numerically. We use order 2 Gaussian quadrature with weights of 1.0 and Gauss points at $(\xi, \eta, \zeta)=( \pm 1 / \sqrt{3}$, $\pm 1 / \sqrt{3}, \pm 1 / \sqrt{3}$ ). The saturated hydraulic conductivity $K_{s}$ is assumed constant over each element.

To evaluate the system integrals in local coordinate space we need to compute the determinant of the Jacobian of the global to local coordinate transformation. For the integrals (10) and (11) we also need the inverse of the Jacobian to compute the derivatives of the basis functions (for instance, $\partial N_{i} / \partial x=\left(\partial N_{i} / \partial \xi\right)(\partial \xi / \partial x)+\left(\partial N_{i} / \partial \eta\right)(\partial \eta / \partial x)+\left(\partial N_{i} f\right.$ $\partial \zeta)(\partial \zeta / \partial x)$ ). The components of the Jacobian and inverse Jacobian will be spatially dependent due to the quadratic and cubic terms in the basis functions. The cost of computing and storing the Jacobian determinant and inverse Jacobian at each Gauss integration point for each element can be quite high for a three-dimensional simulation. For our particular model we could have taken advantage of special features of our catchment discretization to simplify the transformation of (8), thereby minimizing the storage and CPU expenses associated with the Jacobians. For instance, some of the spatial dependencies in (8) can be eliminated when using rectangular elements with the element edges aligned with the global coordinate axes. Furthermore, there are similarities in the Jacobian components from element to element which can be exploited if we use grid spacing in any of the coordinate directions. In the current implementation of the model we use the most general form of the mapping from local to global coordinates, as given by (8), without taking advantage of particular features of our grid geometry.

The Crank-Nicolson finite difference scheme is used to discretize (9) in time. The resulting equation is

$$
\begin{aligned}
\mathbf{A}\left(\boldsymbol{\Psi}^{k+(1 / 2)}\right) \boldsymbol{\Psi}^{k+(1 / 2)} & +\mathbf{F}\left(\boldsymbol{\Psi}^{k+(1 / 2)}\right) \frac{\boldsymbol{\Psi}^{k+1}-\boldsymbol{\Psi}^{k}}{\Delta t} \\
& =\mathbf{q}\left(t^{k+(1 / 2)}\right)-\mathbf{b}\left(\boldsymbol{\Psi}^{k+(1 / 2)}\right)
\end{aligned}
$$

where superscript $k$ represents time level and $\Psi^{k+(1 / 2)}=$ $\left(\Psi^{k+1}+\Psi^{k}\right) / 2$.

Equation (15) is linearized using Picard iteration, which we can write as

$$
\begin{aligned}
\left(\frac{1}{2} \mathbf{A}^{k+(1 / 2),(m)}+\frac{1}{\Delta t} \mathbf{F}^{k+(1 / 2),(m)}\right) & \left(\Psi^{k+1,(m+1)}\right. \\
\left.-\Psi^{k+1,(m)}\right) & =-\mathbf{f}\left(\Psi^{k+1,(m)}\right)
\end{aligned}
$$

where superscript $(m)$ denotes iteration level and

$$
\begin{aligned}
& \mathbf{f}\left(\boldsymbol{\Psi}^{k+1}\right)=\frac{1}{2} \mathbf{A}^{k+(1 / 2)}\left(\boldsymbol{\Psi}^{k+1}+\boldsymbol{\Psi}^{k}\right) \\
& +\mathbf{F}^{k+(1 / 2)} \frac{\boldsymbol{\Psi}^{k+1}-\boldsymbol{\Psi}^{k}}{\Delta t}-\mathbf{q}^{k+(1 / 2)}+\mathbf{b}^{k+(1 / 2)}=\mathbf{0}
\end{aligned}
$$

To solve the linear system of equations represented in (16) we use a conjugate gradient algorithm from ITPACK [Kincaid et al., 1982] with a symmetric successive overrelaxation preconditioner and a compact nonsymmetric storage scheme. The structure of the system matrix resulting from (16) is sparse and symmetric with a maximum of $27\left(3^{3}\right)$ nonzero entries per row. For irregular catchment geometries such as shown in Figure 2 the bandwidth will not be constant over the matrix and can become quite large for some rows.

\subsection{Model Inputs and Representation of Hydrologic Processes}

The catchment simulation model comprises two programs: a grid generator which constructs the finite element mesh and initializes various parameters, and the actual simulation program which numerically solves the three-dimensional Richards equation over a specified time period for a given set of boundary and initial conditions.

The design and structure of the mesh generation and simulation programs were motivated in large part by the availability of digital elevation models (DEMs) of topography from the U.S. Geological Survey. These data bases provide topographic information for extensive geographic regions at high resolution and in regular grid form $(30 \times 30 \mathrm{~m}$ pixels). An automated extraction algorithm [Band, 1986] is applied to the DEM data to produce a mapping of stream channels, ridges, and drainage basins and subbasins. Based on this mapping we can define the boundaries of a catchment, obtain elevation, stream, and distance-to-stream data, and subdivide the catchment into physically consistent subcatchments. Figure 2 is a subcatchment image produced using some of the output from the extraction algorithm. The three shaded pixels in this image show the location of three surface nodes selected for detailed vertical profile output during the numerical simulation and the solid pixels outline the stream network.

The finite element mesh generator was developed to take advantage of the regular grid structure of the digital elevation data and to use the information provided by the extraction algorithm. The mesh generation algorithm discretizes a catchment or subcatchment into hexahedral elements, numbers and connects the nodes and elements, initializes the pointer arrays for storing the system matrices, and sets up the boundary and initial conditions for ensuring simulation. A compact storage scheme is used for the sparse system matrices.

The simulation program takes the information from the grid generator, and for each time step of the simulation period it performs the iterations on the nonlinear equation, sets up and solves the linearized system of equations, calculates mass balance errors, and computes the hydrograph contributions. The simulation program is an extension of the model by Binley et al. [1989a, b].

The geometry of a catchment as defined by the DEM extraction algorithm is based on the location of naturally occurring ridges. The finite element method allows us to model irregular domains so there is no smoothing or transformation applied to redefine the catchment boundaries. The ridges are assumed to represent vertical walls which we consider to be impermeable lateral boundaries, and we also define the base of the catchment as a no-flux boundary. The only boundary conditions which need to be explicitly input 
are those at the surface (precipitation and evaporation rates). This method of treating nonsurface boundaries is a simplifcation of the acutal physical processes, and its validity needs to be examined in more detail. In principle the model can handle any type of boundary condition, but there is often a lack of knowledge and data concerning flow processes across nonsurface boundaries. If we define the vertical extent of a catchment deep enough so as not to affect processes (infiltration, runoff, evaporation) occurring near the surface, or if we know the location of an underlying low-permeability layer, then an impermeable boundary condition at the base of the catchment is justified. Defining a deep catchment and analyzing, for example, the simulated flow behavior near the water table could be one method of determining more suitable boundary conditions when a no-flux condition is inappropriate at the catchment base. A similar method for assessing the validity of the zero-flux condition along lateral boundaries would be to simulate a catchment and examine the computed flow patterns across the ridge boundaries of each of the subcatchments which make up the catchment.

The catchment topography is heterogeneous, with elevation inputs obtained directly from the DEM data. The data are in regular grid form, and we retain this uniform grid structure in defining the $x$ and $y$ (horizontal) dimensions of each element of our numerical grid. The size of each DEM pixel is $\Delta x \times \Delta y=30 \times 30 \mathrm{~m}$, and it is an easy matter to interpolate these data to a finer grid or to aggregate it to a coarser resolution. In our simulations of the $1 \mathrm{D}$ catchment we used linear interpolation to obtain a range of catchment discretizations from $30 \times 30 \mathrm{~m}$ to $1 \times 1 \mathrm{~m}$. Although we use uniform grid spacing horizontally ( $\Delta x=\Delta y$, constant), the vertical discretization $\Delta z$ can be variable. This allows us to define, for instance, thinner layers closest to the surface. The mesh generation program has the option of making the thickness of each layer uniform horizontally (this results in a staggered catchment base), or of making the base of the catchment flat (resulting in horizontally nonuniform layer thicknesses).

To treat flow processes occurring on the catchment surface and in streams we need to couple Richards's equation governing subsurface flow, the shallow water equations for channel flow, and a kinematic or shallow water model for overland flow [Eagleson, 1970; Freeze, 1974]. In the current version of our model we use a simple linear transformation to distribute overland flow. Surface runoff generated at a point on the catchment is routed to the stream via a time delay determined from the overland flow velocity (currently assumed constant for the catchment) and the shortest distance from the point to the stream. The location of the stream and values for the shortest overland paths to the stream ("delay distances") are obtained from the DEM extraction algorithm. We note that this approach does not allow for downslope reinfiltration of overland runoff. This simple treatment of overland flow routing is a reasonable approximation when partial contributing areas are the main source of surface nunoff. These saturated regions will typically grow as an expanded stream network during a rainfall event [Dunne and Black, 1970] so that downslope reinfiltration will not occur and the distances for overland travel will remain relatively short. Streams can be modeled as specified head boundaries (permanent streams), or we can assign stream nodes initially high levels of saturation (ephemeral streams). Channel flow is not considered in the model. Seepage faces and stream banks can be handled numerically [Neuman, 1973; Cooley, 1983; Huyakorn et al., 1986] but are somewhat complicated to discretize in the case where the stream is internal to the catchment rather than being situated along a lateral boundary. Wide internal streams require a dual stream bank configuration, with the location of stream banks and seepage faces autumatically generated from anal$y$ sis of the DEM data. The current implementation of the model does not have this feature.

In addition to heterogeneities in topography it is important to account for variability in the catchment soils and in the atmospheric inputs to the model. At present the model considers only spatial variability in saturated hydraulic conductivity $K_{s}$ and spatial and temporal variability in evaporation and precipitation rates. Other parameters, namely $f$, $\theta_{r}, \theta_{s}, \psi_{s}, n, S_{s}$, and $\psi_{\min }$ described below, are kept constant over the catchment. The extension to spatially variable representation of these parameters is straightforward to implement in the model, although high levels of parameter heterogeneity may adversely affect numerical performance [Ababou et al., 1989]. Values for the soil hydraulic parameters $\theta_{r}, \theta_{s}, \psi_{s}, n$, and $S_{s}$ can be obtained by fitting (2) and/or (4) to observed data or by using other information about the catchment soils. Saturated conductivities are input for each node on the catchment surface, and relationship (5) is used to assign $K_{s}$ values vertically. The value of parameter $f$ can be estimated by fitting observed $K_{s}$ data to (5), as shown later. By allowing spatial and temporal variability in precipitation and evaporation it is possible to simulate alternating periods of soil wetting and drying, and to have rainfall and evaporation occurring simultaneously over different portions of the catchment. For the simulations described in this paper we used spatially homogeneous rainfall and evaporation since the $1 D$ catchment is quite small.

At any surface node the simulation program automatically switches from a specified flux (Neumann) to a constant head (Dirichlet) boundary condition when the node becomes saturated or its pressure head becomes smaller than the "air-dry" pressure head value $\psi_{\min }$ [Hillel, 1980b, p. 121]. The boundary condition switches back to a Neumann type when the magnitude of the flux across the soil surface (computed) exceeds the magnitude of the atmospheric (specified) flux, or when the atmospheric event switches from rainfall to evaporation or evaporation to rainfall. For Dirichlet nodes the flux across the surface is computed by back solving (16) for $q$ after having solved for the pressure heads. Surface boundary conditions are updated in this manner after each nonlinear iteration.

The initial conditions required for a transient simulation are input as nodal pressure head values. The initial head distribution can be obtained by solving a steady state problem, for example. Alternatively, we can generate the initial heads based on knowledge of the initial water table distribution or initial soil saturation deficits. One method of calculating water table depths or saturation deficits uses a topographic index (computed from the digital elevation data) together with surface $K$, values, the exponential parameter $f$, and a base flow parameter [Sivapalan et al., 1987]. A water table depth or soil moisture deficit can be converted into a vertical pressure head distribution using, for instance, a hydrostatic assumption. 
The final group of input parameters to the simulation program are for dynamic time step control, back stepping. monitoring convergence of the nonlinear iterations, and controlling the generation of output for postprocessing. The specified convergence tolerance is $t o l$, and the maximum number of nonlinear iterations allowed during a time step is maxit. In our simulations we used the convergence test $\left\|\boldsymbol{\Psi}^{k+1,(m+1)}-\boldsymbol{\Psi}^{k+1,(m)}\right\|_{\infty} \leq t o l$. The simulation begins with a time step of $\Delta t_{0}$ and proceeds until time $T_{\max }$. The current time step is increased by a factor of $\Delta t_{\text {mag }}$ (to a maximum of $\Delta t_{\max }$ ) if convergence of the nonlinear system is achieved in fewer than maxit ${ }_{2}$ iterations, whereas the time step is decreased by a factor of $\Delta t_{\text {red }}$ (to a minimum of $\Delta t_{\min }$ ) if convergence required more than maxit $_{2}$ iterations. We back step with a reduced time step (factor $\Delta t_{\text {red, }}$ to a minimum of $\Delta t_{\min }$ ) if convergence is not attained (maxit exceeded).

\subsection{Model Outputs}

Catchment simulation output is processed to produce plots, images, and summary statistics. Vertical profiles of pressure head and moisture content are plotted at various times to show, for instance, the water table response during the simulation. Shaded or color images of surface saturation can show the different mechanisms contributing to surface runoff on various portions of the catchment and the growth of partial contributing areas. Surface images of moisture content, pressure head, and flux values can also be easily produced, as can images along nonsurface cross sections of the catchment.

Hydrograph plots of actual and potential catchment inflows and outflows are produced. The potential inflow in a hydrograph plot consists of the precipitation (positive) and evaporation (negative) flux inputs supplied to the model. When the potential flux is positive, the difference between potential and actual soil inflow is the total runoff. Surface runoff is produced when the surface becomes saturated, either due to a rising water table (saturation excess mechanism) or to the infiltration capacity of the soil's falling below the rainfall rate (infiltration excess mechanism) [Freeze, 1974]. In both cases the boundary condition at the node on the surface where saturation occurs switches from a Neumann type (atmosphere-controlled inflow) to a Dirichlet type (soil-controlled inflow). Subsurface runoff in our model is only produced when the soil moisture flux becomes negative across the surface during a rainfall event, that is, when subsurface water exits the soil matrix from a saturated region on the surface. This type of subsurface runoff is sometimes called "return flow" [Dunne and Black, 1970]. The path of return flow to the stream is initially subsurface and becomes overland flow when it emerges at the surface. Without stream banks there is no way to treat seepage face subsurface flow. The stream discharges in a hydrograph plot are the surface and subsurface runoff components routed to the stream via the time delays computed from the overland flow velocity and shortest overland paths to the stream. There is no routing along the stream channel to the catchment outlet.

The convergence behavior (for both the nonlinear iterative scheme and the linear solver) and mass balance errors (absolute and normalized) are plotted for each catchment simulation. These plots can help pinpoint trouble spots in a simulation, which often occur during transition periods between rainfall and evaporation, during heavy rainfall episodes, or when the catchment or catchment surface become highly saturated. Absolute mass balance errors are computed at each time step as the difference between the change in moisture storage in the catchment soil and the net boundary influx (amount of water entering or leaving the catchment at the boundaries). The moisture storage is calculated by integrating the $\theta(\psi)$ (equation (2)) over each element and summing over all elements. In the current version of the model, nonzero boundary fluxes occur only at the catchment surface, so the net influx is obtained using the specified atmospheric rates (for Neumann nodes) or the back solved fluxes (for Dirichlet nodes). Normalized or relative mass balance errors are obtained by dividing the absolute mass balance errors by the net influx (and multiplying the result by 100 for a percentage error).

\section{Simulation of the Konza Prairie ID CATCHMENT}

We apply our three-dimensional numerical model to simulate a subcatchment (catchment "1D") of the Konza Prairie Research Natural Area in northeastern Kansas. Observation data collected during a 1987 field experiment are used to parameterize and calibrate the model.

Whereas extensive streamflow, evaporation (actual rates), and rainfall data were available for the simulation periods of interest, very little soil data specific to the ID subcatchment were collected, and in some cases parameter estimates were made using generic soil characteristics for the region. $\mathrm{Pa}$ rameterization of the model is therefore adequate for the atmospheric boundary conditions but less than satisfactory for the saturated conductivity distribution, soil zone depths, characteristic equations, and initial conditions. Due to lack of data some degree of calibration is needed even though the model is physically based. Moreover, the streamflow component of the $1 \mathrm{D}$ catchment water balance is of much smaller magnitude than water losses due to evaporation, so that model calibration based on observed streamflow hydrographs alone is of limited use. For these reasons a comprehensive and rigorous model assessment, according to procedures such as those described by James and Burges [1982], will not be our focus. Evaluation of possible model errors and a more detailed calibration should be conducted using potential evaporation measurements and soil moisture content data in addition to streamflow observations. Data and measurement error would also need to be quantified and taken into account.

\subsection{Description and Discretization of the Catchment}

The Kings Creek catchment and ID subcatchment are in the Konza Prairie Research Natural Area near Manhattan, Kansas, in the northeastern part of the state (Figure 1). The Konza site, part of the Flint Hills Upland geologial region, is a $34.87 \mathrm{~km}^{2}$ area of native tallgrass (blue stem) prairie and is one of 11 sites selected for the Long-Term Ecological Research (LTER) program of the National Science Foundation [Bhowmik, 1987]. The Konza area has a temperate midcontinental climate with average annual precipitation of about $835 \mathrm{~mm}$. Streamflow is ephemeral with high flows during the winter and late spring but dry in the summer and 
TABLE 1. Discretization of ID Catchment

\begin{tabular}{cccccc}
\hline Catchment & $\begin{array}{c}\text { Grid } \\
\text { Resolution }\end{array}$ & $\begin{array}{c}\text { Number of } \\
\text { Nodes }\end{array}$ & $\begin{array}{c}\text { Number of } \\
\text { Elements }\end{array}$ & $\begin{array}{c}\text { Sparsity, } \\
\%\end{array}$ & $\begin{array}{c}\text { Storage, } \\
\times 10^{6} \text { words }\end{array}$ \\
\hline 1D-30 & $30 \times 30 \mathrm{~m}$ & 1,570 & 1,064 & 98.280 & 0.148 \\
ID-15 & $15 \times 15 \mathrm{~m}$ & 5,795 & 4,256 & 99.534 & 0.549 \\
1D-10 & $10 \times 10 \mathrm{~m}$ & 12,680 & 9,576 & 99.787 & 1.20 \\
1D-06 & $6 \times 6 \mathrm{~m}$ & 34,430 & 26,600 & 99.922 & 3.28 \\
1D-05 & $5 \times 5 \mathrm{~m}$ & 49,295 & 38,304 & 99.945 & 4.70 \\
1D-03 & $3 \times 3 \mathrm{~m}$ & 135,355 & 106,400 & 99.980 & 12.91 \\
\hline
\end{tabular}

late fall except during heavy rainstorms [Engman et al., 1989]. The $1 D$ subcatchment has a surface area of $0.24 \mathrm{~km}^{2}$ and is situated in the southeast corner just off the Kings Creek catchment. The U.S. Geological Survey digital elevation data for the $1 \mathrm{D}$ catchment contain 314 pixels at $30 \times 30$ m resolution.

Soil, streamflow, rainfall, and evaporation data at the Konza site were collected during summer 1987, from late May to mid-October, as part of an international field experiment (the First International Satellite Land Surface Climatology Project Field Experiment, or FIFE) to study landatmospheric interactions for global climate modeling [Sellers et al., 1990]. Using the observation data we applied our catchment model to simulate the 1D subcatchment for a 9-day interstorm sequence (May 29 to June 6, 1987) and for a 17-day period of alternating rainfall and evaporation (June 25 to July 11,1987$)$.

To study aspect ratio constraints we interpolated the $30 \times$ $30 \mathrm{~m}$ elevation data for the ID subcatchment to obtain a range of discretizations from $30 \times 30 \mathrm{~m}$ to $3 \times 3 \mathrm{~m}$, shown in Table 1. We label the $30 \times 30 \mathrm{~m}$ discretized catchment $1 \mathrm{D}-30$, the $15 \times 15 \mathrm{~m} \mathrm{1D}-15$, and so on. Figure 2 is an image of the 1D catchment at a horizontal grid discretization of $10 \times 10 \mathrm{~m}$. The vertical discretization of catchment $1 \mathrm{D}$ was kept fixed at four layers for all simulations, and the number of nodes and elements in the three-dimensional finite element mesh using the different horizontal grid resolutions ranges from $O\left(10^{3}\right)$ to $O\left(10^{5}\right)$. We also interpolated the original elevation data to $2 \times 2 \mathrm{~m}$ and $1 \times 1 \mathrm{~m}$ resolution (yielding finite element grids of approximately 300,000 and $1,200,000$ nodes, respectively), but these grids could not be simulated as the amount of memory needed to run the code exceeded the 25 million word capacity (64-bit words) of the Pittsburgh Supercomputing Center Cray Y-MP computer. The degree of sparsity shown in Table 1 is calculated as $100(1-27 / N)$, where $N$ is the number of nodes and 27 is the maximum number of nonzero entries per row in the system matrices.

\subsection{Observation Data and Parameter Fitting}

The catchment and model parameter values used for the 1D catchment simulations are given in Tables 2 and 3 . The coordinates of three surface nodes designated for detailed vertical profile output are $(x=150 \mathrm{~m}, y=360 \mathrm{~m}),(300,360)$, and $(450,360)$ and correspond, from left to right, to the three shaded pixels shown in Figure 2.

The values of $\psi_{s}, n, f$, and surface $K_{s}$ were obtained by least squares fits of (2) and (5) to observation data, as shown in Figure 3. The soils in part of the Kings Creek catchment are identified as Florence silty clay loams and Benfield silt loams, and we used moisture retention and saturated hy- draulic conductivity data from the Soil Conservation Service of the United States Department of Agriculture (T. Demetriades-Shah et al. unpublished report, 1989) corresponding to Florence and Benfield soils at the FIFE sites. The values for residual moisture content $\theta_{r}$ and porosity $\theta_{s}$ were taken from the estimates for a silty clay loam published by Rawls et al. [1982]. The curve and data in Figure $3 b$ suggest that even at extremely high suction values the soil moisture content does not fall below $20 \%$. The measurements from the Soil Conservation Service shown in this plot were obtained from soil cores taken at depths of $5-10 \mathrm{~cm}$ and $30-70 \mathrm{~cm}$. From near-surface remotely sensed measurements of soil moisture made for the catchment, on the other hand, we do obtain moisture contents below 20\% [Engman et al., 1989]. Aside from measurement error, the discrepancies between the observations made by remote sensing and those obtained from soil cores may indicate differences in the characteristics of the soil near the surface and at depth, in which case these differences should be taken into account in the parameterization of the model.

No measurements of relative hydraulic conductivity, specific storage, or overland flow velocity were made for the 1D catchment, and little information for estimating initial conditions or the horizontal distribution of saturated conductivites was available. The $K_{r}(\psi)$ relationship was obtained from (4) using the parameter values from the $Q(\psi)$ fit shown in Figure $3 b$. We note that $n=1.176$ is just outside the range $1.25<n<6$ suggested by van Genuchten and Nielsen [1985] for the validity of (4) and of the relationship $m=1-1 / n$, so it will be important to validate the $K_{r}(\psi)$ relationship with experimental data. The horizontal distribution of saturated hydraulic conductivities was assumed to be spatially homogeneous. For the 17-day precipitation-evaporation simula-

TABLE 2. Soil and Grid Parameter Values for ID Catchment Simulations

\begin{tabular}{lc}
\hline \multicolumn{1}{c}{ Parameter } & Value \\
\hline$\theta_{r}$ & 0.04 \\
$\theta_{s}, \mathrm{~m}$ & 0.471 \\
$\psi_{s}, \mathrm{~m}$ & -0.741 \\
$n$ & 1.176 \\
$S_{s}, \mathrm{~m}^{-1}$ & 0.001 \\
$\psi_{\min }, \mathrm{m}$ & $-999.9^{\prime \prime}$ \\
Surface elevation range, $\mathrm{m}$ & {$[417.0,442.0]$} \\
$\Delta x, \Delta y, \mathrm{~m}$ & $3.0,5,6,10,15,30.0$ \\
& $(1 \mathrm{D}-03,1 \mathrm{D}-05, \cdots, 1 \mathrm{D}-30)$ \\
$\Delta, \mathrm{m}$ & 1.0 \\
$\Delta z, \mathrm{~m}$ & 0.2 \\
Top two layers & 0.3 \\
Boltom two layers & 4.0 \\
Overland flow velocity, $\mathrm{m} / \mathrm{h}$ & \\
\hline
\end{tabular}


TABLE 3. Saturated Conductivity, Time Step, and Convergence Parameter Values for ID Catchment Simulations

\begin{tabular}{lccc}
\hline \multicolumn{1}{c}{ Parameter } & $\begin{array}{c}\text { 17-Day Precipitation- } \\
\text { Evaporation Simulation }\end{array}$ & $\begin{array}{c}\text { 9.Day } \\
\text { Evaporation Simulation }\end{array}$ & $\begin{array}{c}\text { 12-Hour } \\
\text { Evaporation Simulation }\end{array}$ \\
\hline Surface $K_{s}, \mathrm{~m} / \mathrm{h}$ & 0.2180 & 0.0218 & 0.0218 \\
$f, \mathrm{~m}^{-1}$ & 3.526 & 3.526 & 3.526 \\
$T_{\max }$, hours & $408.0(17$ days $)$ & $216.0(9$ days $)$ & $12.0(0.5$ days $)$ \\
$\Delta t_{0}$, hours & 0.05 & 0.10 & 0.10 \\
$\Delta t_{\min }$, hours & 0.0005 & 0.01 & 0.0001 \\
$\Delta t_{\max }$, hours & $1.0^{*}, 2.0 \dagger$ & 12.0 & 3.0 \\
$\Delta t_{\text {ma }}$ & 0.5 & 0.5 & 0.5 \\
$\Delta t_{\operatorname{mas}}$ & 1.2 & 1.2 & 1.2 \\
col, m & 0.005 & 0.05 & 0.0005 \\
maxit & 8 & 12 & 12 \\
maxit & 5 & 6 & 6 \\
\hline
\end{tabular}

*Simulation using 15 -min rainfall rates.

†Simulation using daily-averaged rainfall rates.

tion we assumed fairly wet antecedent moisture conditions and tried various distributions of initial conditions. Varying the initial conditions, however, did not have as great an effect on the simulated catchment discharge rates as variations in surface $K_{s}$. For the 9-day evaporation simulation we assumed the catchment was completely saturated at the start (based on high streamflows observed in the days just prior to the interstorm period, with a peak rate of approximately 26 $\mathrm{m}^{3} / \mathrm{h}$ ), and we used a vertically hydrostatic initial pressure head distribution. We used values of $0.001 \mathrm{~m}^{-1}$ for specific storage and $4.0 \mathrm{~m} / \mathrm{h}$ for overland flow velocity, which will require verification. The average soil depth of the $1 D$ catchment has been estimated to be $0.76 \mathrm{~m}$ [Blain, 1989], although

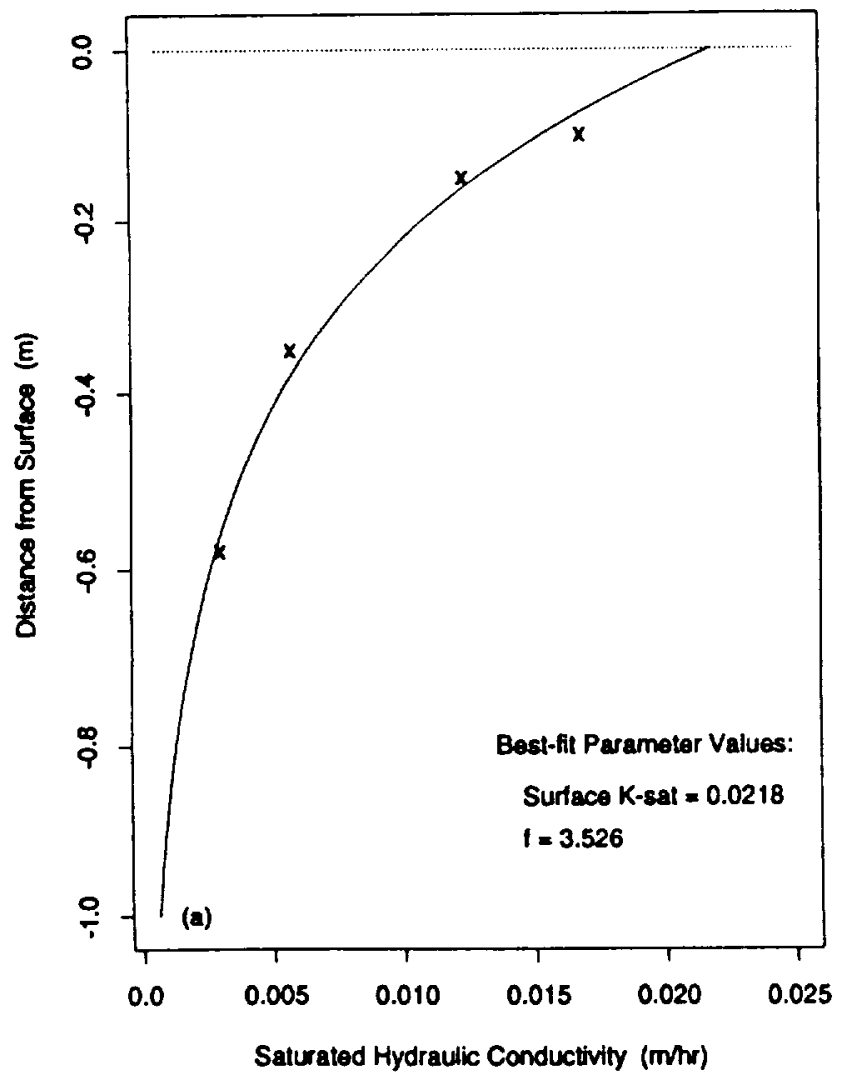

we used a uniform value of $1.0 \mathrm{~m}$ in our simulations. We discretized the catchment vertically into four layers with two thin layers $(0.2 \mathrm{~m})$ near the surface and two thicker layers $(0.3 \mathrm{~m})$ at the base of the catchment.

Since catchment 1D is quite small we assumed spatial homogeneity for the atmospheric inputs to the model. Precipitation data were collected at 32 rain gauges on the Kings Creek FIFE site, and we averaged the data from the two gauges closest to the ID catchment. Evaporation measurements were made during four separate periods over the summer and represent actual rather than potential soil moisture losses to the atmosphere. In the absence of potential evaporation rates it was necessary to set the air-dry pressure

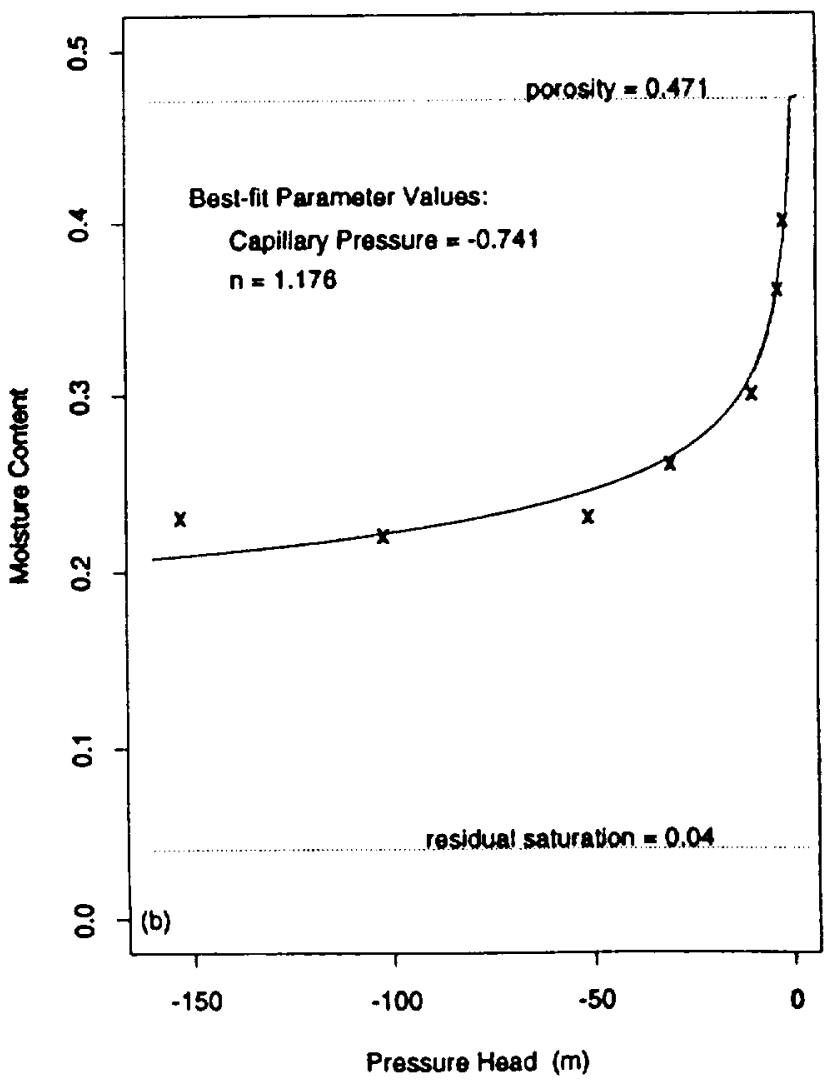

Fig. 3. Least squares fits (solid lines) of the $(a) K_{s}(z)$ and $(b) \theta(\psi)$ relationships to observed data (crosses). 


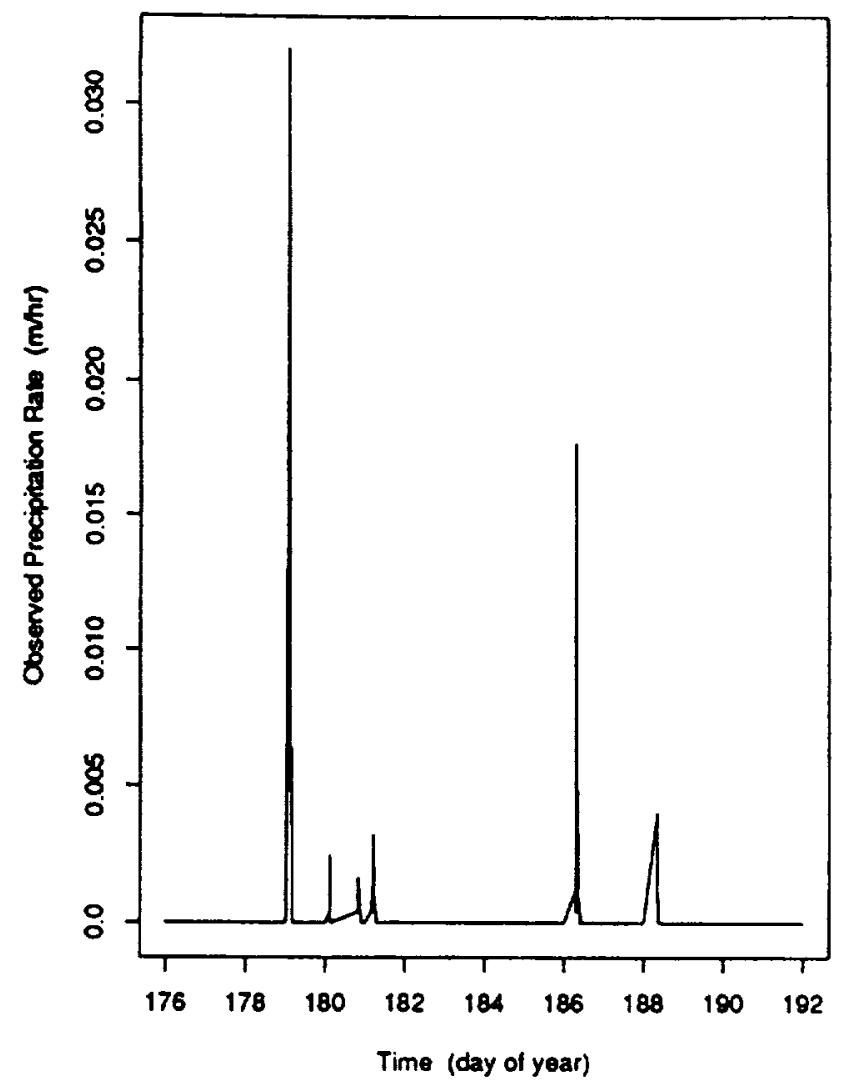

Fig. 4. Observed precipitation data for the 17-day rainfallinterstorm period June 25,1987 (day 176) to July 11, 1987 (day 192).

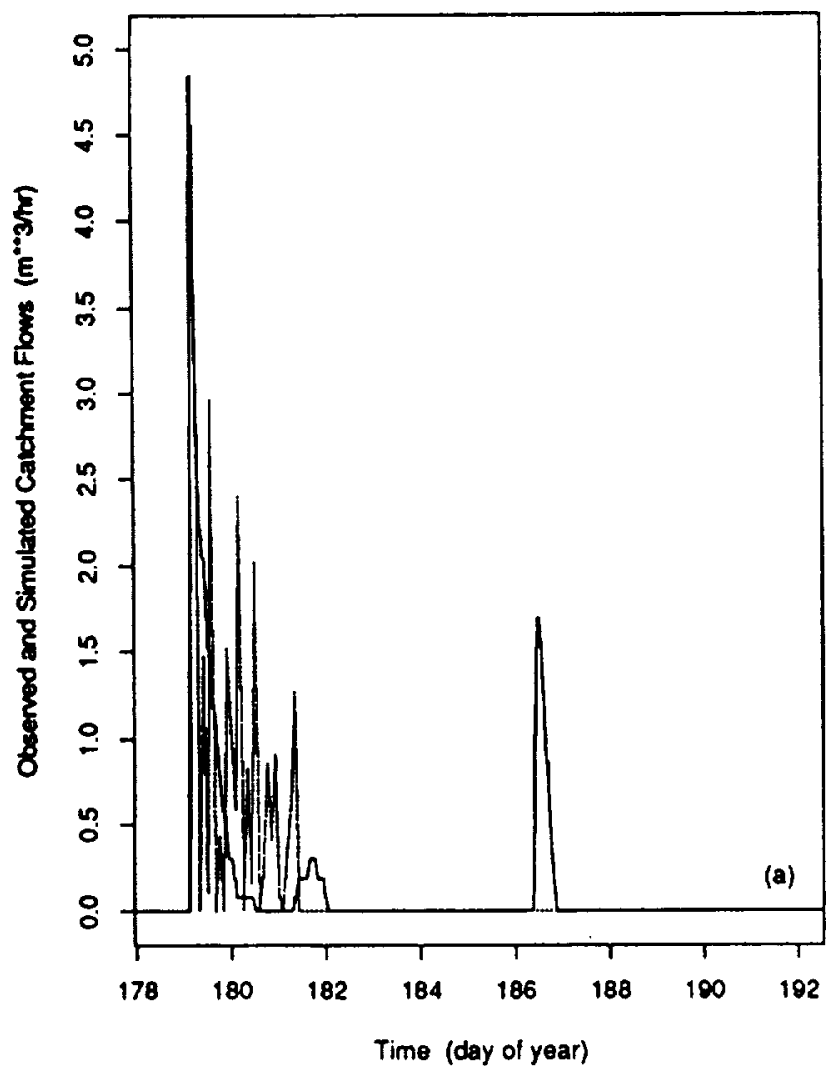

head value $\psi_{\min }$ to an arbitrarily small value (indicated as " -999.9 " in Table 2) to ensure that evaporation remained atmosphere controlled throughout the simulation period, with the atmospheric evaporation rate equal to the actual (observed) rate. If potential evaporation data were available and an estimate of $\psi_{\min }$ could be made, an important check on the performance of the model would be to run a simulation using the potential rates as input boundary conditions and allowing the model to switch from atmosphere- to soil-controlled evaporation, so that the computed actual evaporation rates could be compared with the observed actual rates.

\subsection{Simulation of 17-Day Rainfall-Interstorm Sequence}

The precipitation, evaporation, and streamflow observation data used for the 17-day rainfall-interstorm simulation (June 25 to July 11,1987 ) is shown in Figures 4 and 5 . We used daily-averaged evaporation rates (Figure $5 b$ ) and had to interpolate the average rates for days 179 and 180 due to insufficient observation data for these two days. There were two major rain events during the 17-day period (Figure 4), on June $28(17.14 \mathrm{~mm})$ and July $5(10.23 \mathrm{~mm})$. In addition, between 2.3 and $3.5 \mathrm{~mm}$ of rain was recorded for three smaller precipitation events which occurred on June 29, June 30 , and July 7 . Several storms also occurred during the week ending June 25 , delivering $11.5,21.2,7.2$, and $21.5 \mathrm{~mm}$ of rain on June $18,20,22$, and 24 respectively. These large rainstorms immediately prior to June 25 enabled us to assume fairly wet initial soil conditions for the simulation.

Fig. 5. (a) Observed streamflow (solid line) and simulated discharge (dotted line), and (b) comparison of streamflow (solid line), evaporation (dotted line with crosses), and precipitation (dashed line) components of the catchment water balance for the 17-day rainfall-interstorm period ending July 11, 1987 (day 192). 
There were no observation data to verify the initial pressure head distributions used for the simulations, so the initial conditions can be considered somewhat arbitrary. We found, however, that varying the initial conditions did not have as great an effect on the simulated catchment discharge rates as variations in other model parameters.

We ran two series of simulations using the 17-day rainfallevaporation data. In the first series we used detailed, 15-min rainfall rates (Figure 4 ) and attempted to match the observed streamflow record. There are two distinct discharge events in the streamflow hydrograph (Figure $5 a$ ), in response to large storms on June 28 and July 5 . Since the two discharge events appear to be responses to independent storms, we calibrated the model to match the June 28 event and then used these calibration results to attempt a match of the July 5 event. We remark that for proper model calibration and verification we should use additional observation sequences, encompassing a wide range of scenarios, though given the field data limitations described earlier we were unable to conduct more extensive tests. Furthermore, calibration based on streamflow observations alone is of limited use, as can be ascertained when we examine the relative contributions of the various components of the catchment water balance. We see in Figure $5 b$ that the rainfall and evaporation components are at least an order of magnitude larger than the streamflow component for the 17-day period of interest. It is apparent that almost all of the rainfall occurring during this period infiltrates the soil and only a small part reaches the stream as overland flow or rapid subsurface flow.

The simulations of the 17-day period enabled us to examine the sensitivity of model response to variations in parameters and inputs. In particular, some preliminary tests on time aggregation effects were conducted in a second series of simulations. In these tests we used daily-averaged rainfall rates (Figure $5 b$ ), and we compared the hydrologic and numerical behavior with results from the simulations using detailed 15-min rain rates. We obtained significant discrepancies in surface saturation response during the storm events, but overall the simulated hydrologic responses using the averaged and detailed rain rates were quite similar. The advantage of using averaged rates for atmospheric inputs is that larger time steps can be used, making the simulation cheaper to run. Averaged rates also produce smoother boundary conditions which can reduce numerical difficulties. On the other hand, the high degree of variability in atmospheric fluxes may make it necessary to use detailed inputs, depending on the hydrologic responses of interest. For instance, large discharge events triggered by infiltration excess overland flow will be very sensitive to small-scale fluctuations in precipitation rates.

The results from the first series of simulations are shown in Figure $5 a$. We were able to approximately match the observed peak, volume, and duration of streamflow response for the June 28-30 rainfall events, but the model produced no discharge for the July 5 storm. Note that the model result shown is total discharge, which is surface runoff routed to the stream. The model does not consider channel flow, and thus we could not compute streamflow rates at the catchment outlet. The lack of a channel flow component, along with the linear and discrete method used in the model to route and delay overland flow (surface runoff produced on $30 \times 30 \mathrm{~m}$ grid blocks is accumulated without downslope reinfiltration into 2-hour hydrograph intervals), may account for the fluctuations in the computed discharge shown in Figure $5 a$. The results for the first two days of the 17-day simulation are not shown in Figure $5 a$. There is streamflow activity on these first two days in response to the rain events which occurred during the week ending June 25 , but we do not explicitly account for these rain events in the 17-day simulation.

The model was first run using the parameter values obtained from observation data (Figure 3 and Tables 2 and 3 ), but this produced an excessive amount of surface runoff. To calibrate the model we systematically altered the values of some of the parameters: soil depth $L$, vertical discretization $\Delta z$, overland flow velocity, saturated conductivity $K_{s}$ at the surface, fitting parameter $f$ for vertical exponential $K_{s}$, time steps, and initial conditions. We found that only overland flow velocity and surface $K_{s}$ had significant effects on the simulated discharge: overland flow velocity on the duration of the discharge response and surface $K_{s}$ on the peak rate and total volume of discharge. Vertical discretization will have some effect on simulated discharge in the case where infiltration excess runoff production is dominant. This type of runoff is controlled by surface $K_{s}$, and in the model we evaluate relationship (5) at the midpoint of each element so that a thin surface layer will have a higher saturated conductivity than a thicker surface layer, thereby potentially reducing infiltration excess runoff. We found, however, that even using a 19-layer vertical discretization with the layer nearest to the surface $0.02 \mathrm{~m}$ thick (compared to $0.2 \mathrm{~m}$ for the four-layer discretization), the model still produced too much runoff. To reduce the amount of runoff it was necessary to increase surface $K_{s}$ from its fitted value of 0.0218 $\mathrm{m} / \mathrm{h}$. We obtained best results using a value of $0.218 \mathrm{~m} / \mathrm{h}$ (for the four-layer discretization). This higher value may be justified considering the remarks made earlier regarding the discrepancies between near-surface remotely sensed soil moisture observations and deeper measurements obtained from soil core analyses, since these discrepancies suggest that the soil near the catchment surface may be very porous. With surface $K_{s}=0.218 \mathrm{~m} / \mathrm{h}$, an overland flow velocity of $0.4 \mathrm{~m} / \mathrm{h}$, and all other parameter values as determined from observation data, we obtained the match shown in Figure $5 a$. To match the streamflow response for July 5 it was necessary to run a separate simulation using surface $K_{s}=$ $0.06 \mathrm{~m} / \mathrm{h}$. The need for different surface $K_{s}$ values to match separate discharge events suggests that it may be important to collect and incorporate information on the spatial distribution of hydraulic conductivity for the ID catchment. Note that since we altered surface $K_{s}$ from the value obtained by parameter fitting (Figure $3 a$ ) we should have refit parameter $f$ to the observation data using the modified value of surface $K_{s}$. This was not done for the simulations reported here.

The surface runoff which generated discharge during the 17-day simulation was initially of the infiltration excess type, in response to peak rainfall rates on June 28 , and later of the saturation excess variety, in response to declining rates but continued rainfall on June 29 and 30 . This can be seen in Figure 6, where infiltration excess saturation is shown by heavily shaded areas, saturation excess by solid areas, and unsaturated portions of the catchment surface by lightly shaded areas. Note the high degree of surface saturation at the start of the simulation (day 176.0) owing to the wet initial conditions which were used. The initial conditions were 

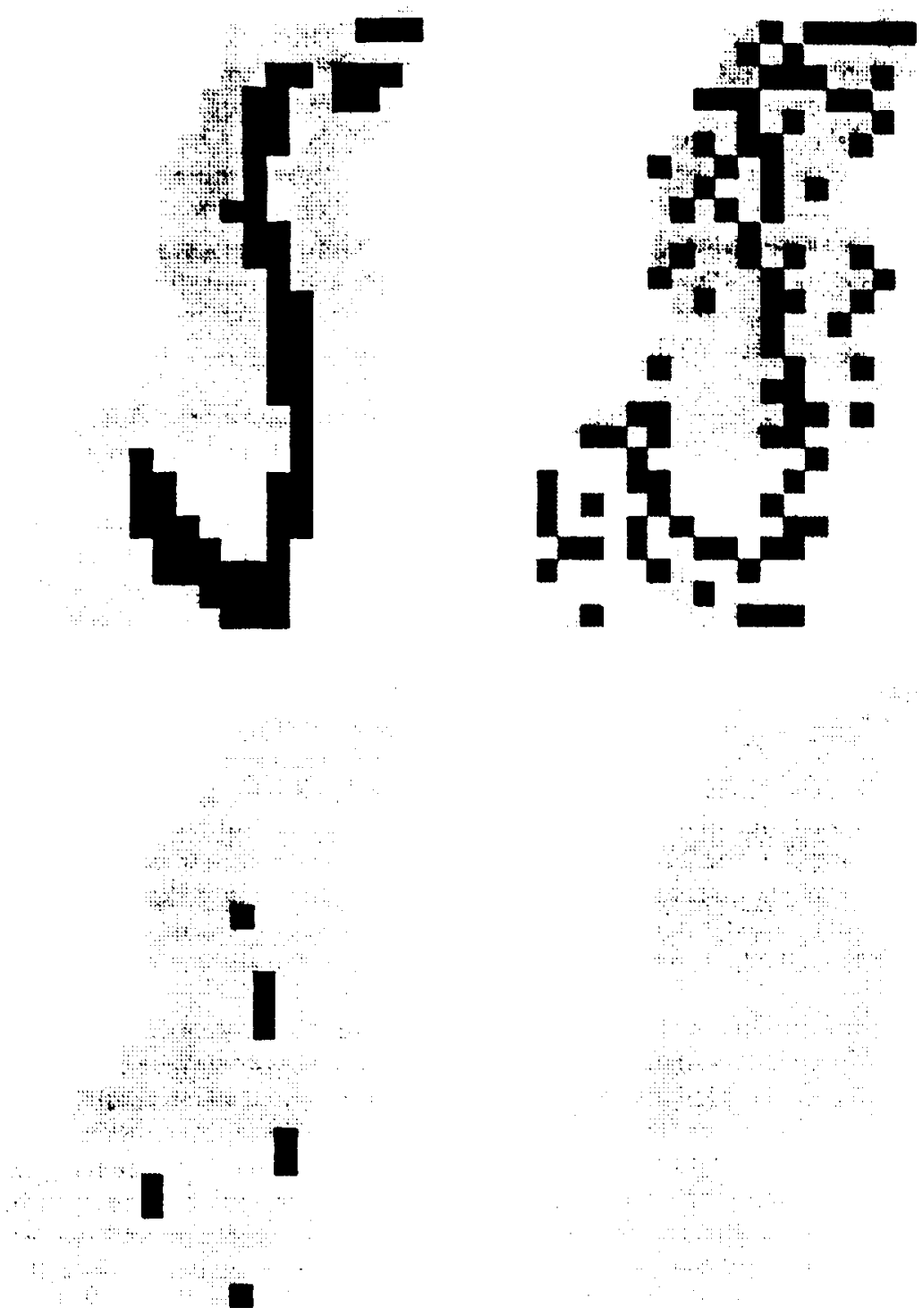

Fig. 6. Surface saturation response for the 17-day precipitation-evaporation simulation, using 15-min rainfall rates: (Top left) day 176.0 (June 25, 1987, initial conditions); (top right) day 179.103; (bottom left) day 181.280; and (bottom right) day 193.0. Light shading indicates unsaturated; heavy shading, infiltration excess; and solid regions, saturation excess.

generated using a topographic index method as described previously, producing the wettest soils closest to the stream channel and catchment outlet. Since rainfall rates and saturated hydraulic conductivities were horizontally homogeneous, infiltration excess runoff occurred first where nearsurface pressure head gradients were lowest, corresponding roughly to the wetter near-stream regions. The patchiness in the infiltration excess pattern seen in Figure 6 is probably due to oscillations in the surface boundary condition switching mechanism from one iteration to the next, oscillations which were caused by approximation errors in the back solved surface flux values. Saturation excess runoff occurred where water table levels were closest to the surface, corresponding once again to near-stream regions. These partial contributing areas then expanded upslope from the catchment outlet and outward from near-stream areas in response to continued rainfall.

It is not surprising that we found high sensitivity to surface
$K_{s}$ in the simulated discharge given that infiltration excess is a dominant mechanism for surface runoff generation. In fact, when we used daily-averaged rainfall rates we failed to generate any infiltration excess runoff, and consequently the simulated discharge hydrograph had a smaller peak and less volume and was of shorter duration than the observed streamflow hydrograph. The simulation with daily-averaged rates also produced less saturation excess overland flow. The different responses during periods of heavy rainfall can be seen in the vertical profiles of presssure head and moisture content shown in Figure 7 . These vertical profiles are taken at the three selected surface nodes of Figure 2. In these plots we can see that the daily-averaged rainfall rates yielded drier soils during the storm on day 179. (The time value for the profiles labeled 179.1 in Figure 7 is actually 179.105 for the $15-\mathrm{min}$ rainfall rate case and 179.162 for the daily-averaged case; for the profiles labeled 188.5 the actual time is 188.461 for the $15-\mathrm{min}$ case and 188.496 for the 

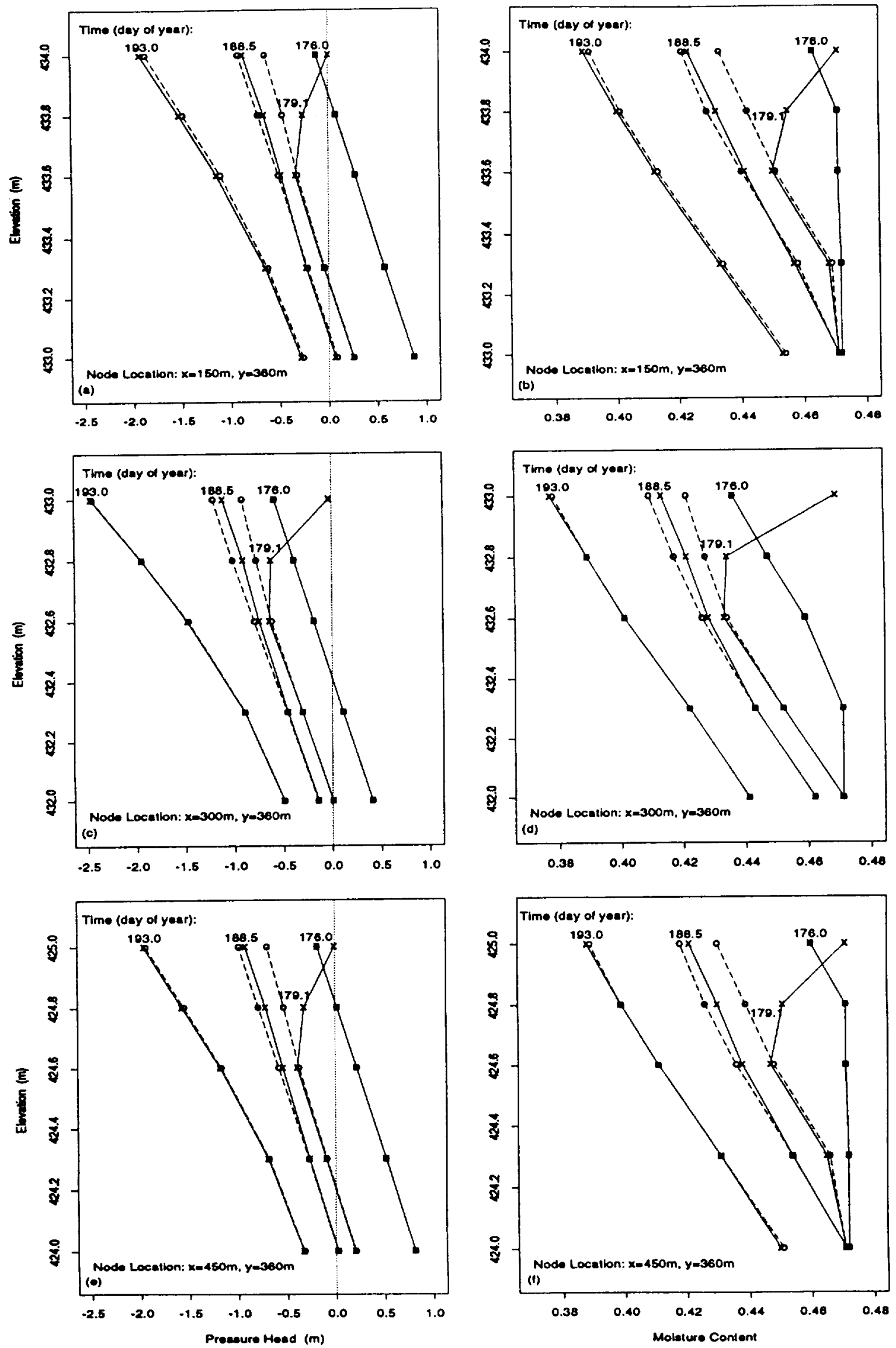

Fig. 7. Vertical profiles for the 17-day precipitation-evaporation simulation, using 15-min (solid lines) and dailyaveraged (dashed lines) rainfall rates. (Day 176 is June $25,1987$. ) 
daily-averaged case.) Aside from discrepancies in surface saturation results during heavy rainfall periods, the hydrologic responses were generally quite similar between the simulations using averaged and detailed precipitation rates. This can be seen in Figure 7 for the profiles at day 188.5 and at the end of the simulation (day 193.0).

The main difference in numerical behavior between the averaged and detailed simulations was that the simulation using 15 -min rates required significantly more CPU time, since smaller time steps had to be used to resolve the detailed rainfall rates. The numerical results are shown in the convergence and mass balance plots of Figure 8 and are summarized in the second and third columns from the left in Table 4. The simulation using detailed rainfall rates had some difficulty during the peak rainfall/saturation periods on June 28 and July 5 , as evidenced by the slower convergence and higher mass balance errors seen in Figure 8. Outside of these two periods the number of nonlinear (Picard) iterations remained roughly constant at two or three and the number of linear (conjugate gradient) iterations decreased steadily as the simulation progressed. The 17-day rainfall-interstorm simulation of the $1 D$ catchment required $19 \mathrm{~min}$ of CPU using 15 -min rainfall rates and $6.5 \mathrm{~min}$ using daily-averaged rates.

\section{Sensitivity to Model Resolution}

\subsection{Statement of the Problem}

In this section we examine the feasibility of using a detailed physically based model for catchment scale simulations. In particular, we will investigate computational issues related to model resolution by simulating the ID subcatchment over a range of grid sizes and convergence tolerance valucs. In a study of discretization cfrects for a twodimensional hillslope model, Calver and Wood [1989] recommended using $\Delta x / \Delta z \leq 20$ for successful numerical simulations. In the results presented below we obtained satisfactory results using aspect ratios as high as $150(\Delta x=$ $\Delta y=30 \mathrm{~m}, \Delta z=0.2 \mathrm{~m})$. However, when we imposed a stricter convergence criterion on the nonlinear iterations, simulations with different aspect ratios produced different mass balance and convergence results.

The 1D subcatchment is small enough that it was not necessary to extrapolate the $30 \times 30 \mathrm{~m}$ digital topographic data to coarser horizontal discretizations, but for larger catchments it will be necessary to examine whether aspect ratios even greater than 150 can be used. Large aspect ratios will also arise when a very fine vertical resolution is required to accurately reproduce runoff and moisture front responses from rainfall and evaporation events. Small vertical grid sizes may in turn lead to stability-related restrictions on time step, further increasing the cost of running large-scale catchment simulations.

The effect of heterogeneities on numerical and physical grid constraints also needs to be investigated. For instance, while a fine grid may be needed to resolve hydrologic responses to highly variable inputs, a large problem size and high parameter variability may lead to ill-conditioned model equations which may adversely affect numerical convergence. Ababou et al. [1989] discuss related heterogeneity effects in the context of a three-dimensional finite difference model applied to steady state saturated flow problems.

\subsection{Simulation of 9-Day Interstorm Sequence}

In Figure 9 we show the evaporation and streamflow observation data for the 9-day interstorm period from May 29 (day 149) to June 6, 1987 (day 157). There was no rainfall on the Kings Creek catchment during this period, except for a very small amount $(1 \mathrm{~mm})$ on May 29 . There was high streamflow just prior to day 149 , and although we had no rainfall observation data prior to May 29 we assumed that there was significant rainfall immediately prior to this date, and we therefore started the 9-day simulation from saturated conditions. We used daily-averaged evaporation rates rather than detailed, diurnally fluctuating rates. This allowed us to use large time steps (up to 12.0 hours), although we observe that the streamflow record in Figure 9 is oscillatory with a periodicity of approximately 1 day, which may be a response to the diurnal fluctuations in evaporation. Due to insufficient data for days 149, 153, and 154 we interpolated average evaporation rates for these days from the observed rates on surrounding days.

We ran two series of simulations using the evaporation data. In the first series we simulated the entire 9-day period for a range of mesh discretizations from 1D-30 to 1D-03. This was done to study the effects of aspect ratio on catchment simulation responses, in particular to determine whether we can successfully run a catchment scale simulation using aspect ratios as large as 150 (corresponding to catchment 1D-30). In the second series of tests we used only the first 12 hours of the 9-day interstorm record and ran simulations of catchments 1D-30 and 1D-05 using a strict convergence criterion for the nonlinear iterations $(t o l=0.0005 \mathrm{~m}$ compared to $t o l=0.05 \mathrm{~m}$ used for the 9-day simulations).

The results from the first series of simulations are presented in Figures 10 and 11 and summarized in the fourth, fifth, and six columns from the Icft in Table 4 . In the figures we compare the 1D-30 and 1D-03 catchment simulations, and in the table we include also statistics from the 1D-10 simulation. Similar results were obtained for catchments ID-15, ID-06, and ID-05.

In Figure 10 we show vertical profiles of pressure head and moisture content at the three selected surface nodes of Figure 2. There is reasonable agreement between the results obtained using a $30 \times 30 \mathrm{~m}$ grid discretization (aspect ratio of 150 ) and the results using a grid resolution of $3 \times 3 \mathrm{~m}$ (aspect ratio of 15 ). We note also the similarities in the profiles at the three different locations owing to the spatial uniformity of atmospheric input rates, initial conditions, and parameter distributions.

The differences in aspect ratio did not have significant effects on the numerical performance of the model. In the fourth, fifth, and sixth columns from the left in Table 4 we observe close agreement for the 1D-30, 1D-10, and 1D-03 simulations. All three simulations were successfully completed in 40 time steps, and none of the runs encountered difficulties severe enough to require back stepping. All simulations required between two and four nonlinear iterations to converge and an average of about 14 iterations to solve the linearized system of equations. In each case, convergence of the linear solver was slowest at the start of the simulation (20-25 iterations) and much more rapid by the end of the simulation (three to five iterations). Similar mass balance results were obtained for each of the simulations, with the largest discrepancies occurring during the first few 

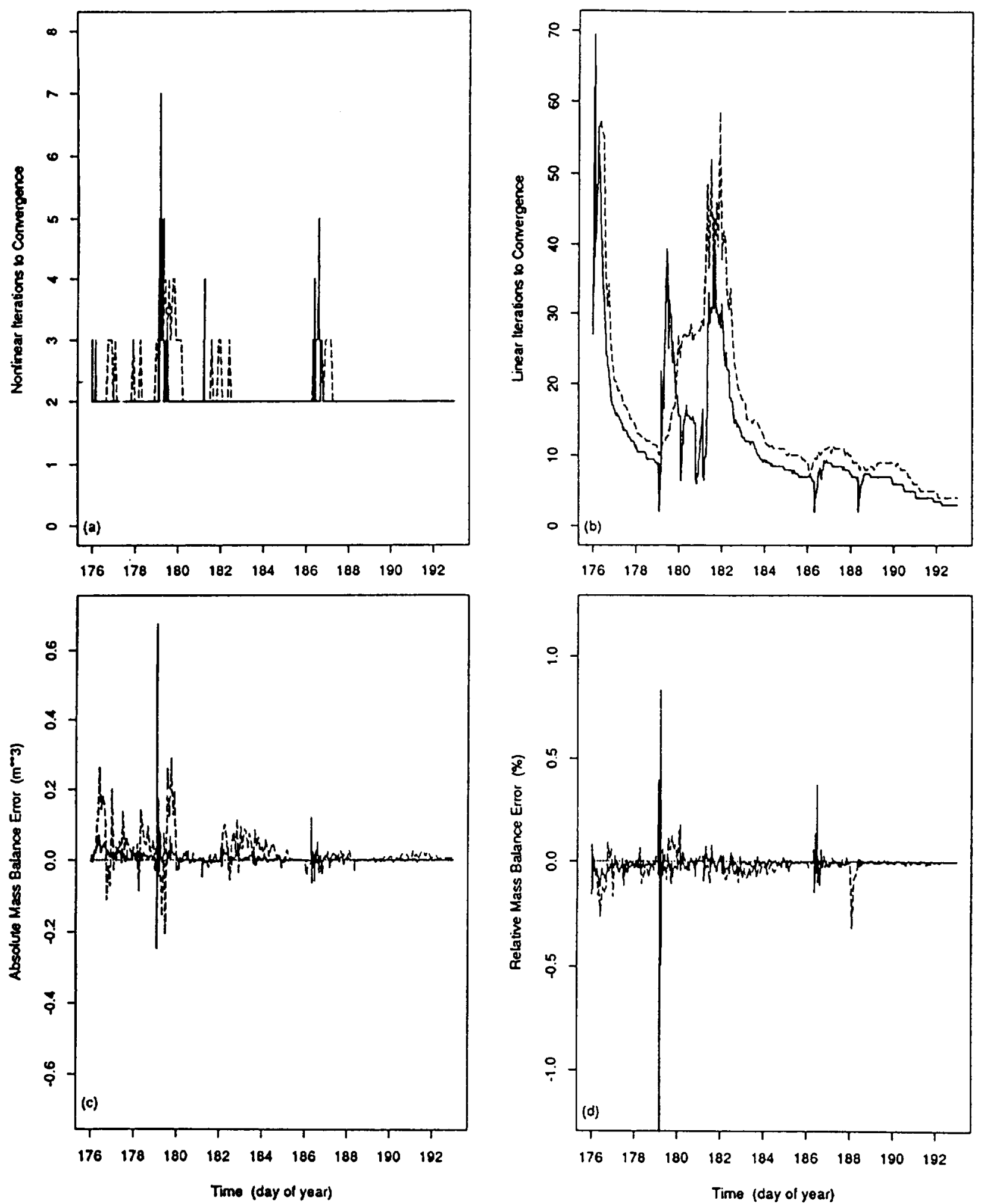

Fig. 8. Convergence and mass balance results for the 17-day precipitation-evaporation simulation, using 15-min (solid lines) and daily-averaged (dashed lines) rainfall rates. In Figure $8 d$ the peak value for the solid curve is $-3.47 \%$. (Day 176 is June 25,1987 .)

time steps. These discrepancies at the start of the simulation, which can be seen in Figure 11, account in large part for the differences in average mass balance errors reported in Table 4. High relative mass balance errors were obtained at the third time step (238\% for catchment $1 D-03$ and $-40.5 \%$ for (D-30), values much larger than the errors computed at all other time steps. We note that average mass balance errors were significantly lower for the 17-day rainfall-interstorm 
TABLE 4. Summary of ID Catchment Simulation Results

\begin{tabular}{|c|c|c|c|c|c|c|c|}
\hline & \multicolumn{2}{|c|}{$\begin{array}{l}\text { 17-Day Precipitation-Evaporation } \\
\text { Simulation (Catchment ID-30) }\end{array}$} & \multicolumn{3}{|c|}{ 9-Day Evaporation Simulation } & \multicolumn{2}{|c|}{$\begin{array}{l}\text { 12-Hour Evaporation } \\
\text { Simulation }\end{array}$} \\
\hline & $\begin{array}{l}\text { 15-min Averaged } \\
\text { Rainfall Rates }\end{array}$ & $\begin{array}{l}\text { Daily-Averaged } \\
\text { Rainfall Rates }\end{array}$ & $\begin{array}{c}\text { Catchment } \\
1 \mathrm{D}-30\end{array}$ & $\begin{array}{l}\text { Catchment } \\
\text { ID-10 }\end{array}$ & $\begin{array}{l}\text { Catchment } \\
\text { 1D-03 }\end{array}$ & $\begin{array}{l}\text { Catchment } \\
\text { ID-30 }\end{array}$ & $\begin{array}{l}\text { Catchment } \\
\text { ID-05 }\end{array}$ \\
\hline Number of nodes & 1,570 & 1,570 & 1,570 & 12,680 & 135,355 & 1,570 & 49,295 \\
\hline Number of time steps & 663 & 223 & 40 & 40 & 40 & 81 & 201 \\
\hline Number of back steps & 1 & 1 & 0 & 0 & 0 & 16 & 50 \\
\hline CPU, s & $1,150.3$ & 391.4 & 66.84 & 583.9 & $6,452.6$ & 215.5 & $19,597.0$ \\
\hline CPU/time step/node & 0.00111 & 0.00112 & 0.00106 & 0.00115 & 0.00119 & 0.00169 & 0.00198 \\
\hline $\begin{array}{l}\text { Nonlinear iterations/time } \\
\text { step }\end{array}$ & 2.26 & 2.17 & 2.40 & 2.48 & 2.53 & 2.56 & 2.64 \\
\hline $\begin{array}{l}\text { Linear iterations/nonlinear } \\
\text { iteration }\end{array}$ & 11.08 & 18.39 & 13.92 & 13.69 & 14.78 & 8.91 & 7.47 \\
\hline $\begin{array}{l}\text { Average |absolute } \mathrm{MBE} \mid, \mathrm{m}^{3} \\
\text { Average |relative } \mathrm{MBE} \mid, \%\end{array}$ & $\begin{array}{l}0.012 \\
0.038\end{array}$ & $\begin{array}{l}0.031 \\
0.034\end{array}$ & $\begin{array}{l}2.927 \\
2.021\end{array}$ & $\begin{array}{l}3.044 \\
5.960\end{array}$ & $\begin{array}{l}3.284 \\
7.255\end{array}$ & $\begin{array}{l}0.00764 \\
0.233\end{array}$ & $\begin{array}{l}0.00081 \\
0.070\end{array}$ \\
\hline
\end{tabular}

Convergence parameter $t o l=0.0005 \mathrm{~m}$. MBE denotes mass balance error.

simulation than for the 9-day interstorm simulation (compare the second and third columns from the left in Table 4), owing to a smaller value of $t o l$ and smaller time steps used for the 17-day simulation.

The importance of not being limited by aspect ratio constraints in a catchment scale simulation is suggested by the storage requirements shown in Table 1 and by the CPU results shown in the fourth, fifth, and sixth columns, from the left in Table 4 . With a grid resolution of $30 \times 30 \mathrm{~m}$ we were able to simulate the 9-day evaporation sequence in

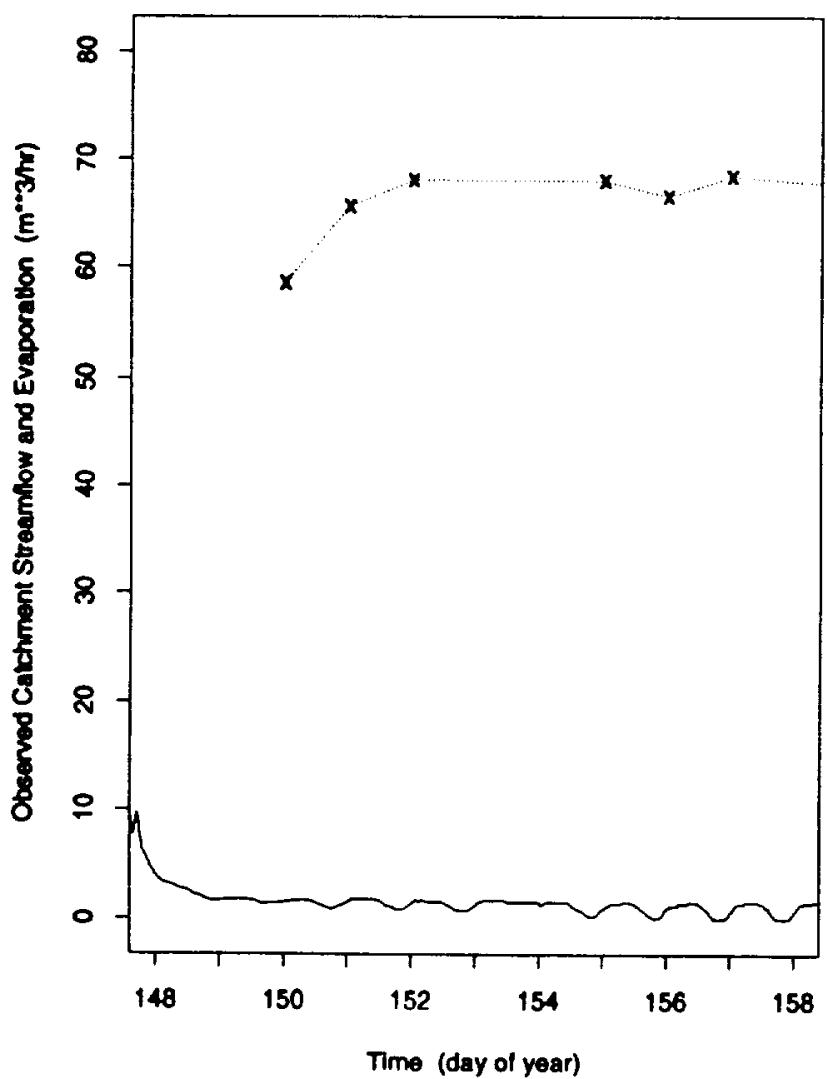

Fig. 9. Evaporation (dotted line with crosses) and streamflow (solid line) observation data for the 9-day interstorm period May 29. 1987 (day 149) to June 6, 1987 (day 157). slightly more than 1 min of computer time, requiring $O\left(10^{5}\right)$ words of memory. The same 9-day simulation with grids of $3 \times 3 \mathrm{~m}$ required over $100 \mathrm{~min}$ of CPU and similarly 100 times more memory.

The results from the second series of simulations, using tol $=0.0005 \mathrm{~m}$ and the first 12 hours of the evaporation period, are summarized in the two rightmost columns in Table 4 . These results can be roughly compared to the results in the fourth, fifth, and sixth columns from the left in Table 4 for the 9 -day, $t o l=0.05 \mathrm{~m}$ simulation. In reducing $t o l$ we have increased the accuracy of the simulations, decreasing by about 2 orders of magnitude the resulting mass balance errors. However, this gain is achieved at the expense of a substantial increase in CPU. For catchment 1D-30 we simulated the 9-day evaporation period in 40 time steps and $67 \mathrm{~s}$ of CPU s with no occurrences of back stepping, while the 12-hour simulation required twice as many time steps, frequent back stepping, and over $200 \mathrm{~s}$ of CPU. For catchment 1D-05 the 12-hour simulation required 5.5 hours of CPU.

We observe from the two rightmost columns in Table 4 that catchment 1D-05 has more trouble converging than catchment ID-30 (201 time steps and 50 back stepping occurrences compared to 81 steps and 16 back steps for ID-30) and that it achieves smaller mass balance errors than 1D-30. In this case the differences in aspect ratio (150 for catchment 1D-30 and 25 for 1D-05) had an effect on the convergence of the nonlinear iterations and on the accuracy of the simulation results (as reflected in the mass balance errors).

\section{Summary and Concluding Remarks}

We have described a three-dimensional physically based numerical model for the simulation of hydrologic processes at the subcatchment and catchment scales. The simulation model consists of a grid generator and a finite element code. The grid generator makes use of catchment information extracted from digital topographic data, and the numerical code is based on the nonlinear Richards equation for flow in variably saturated porous media. The model can be applied to catchments of arbitrary geometry and topography. Nonsurface boundaries are considered impermeable, and grid spacing is uniform horizontally but can be variable along the 

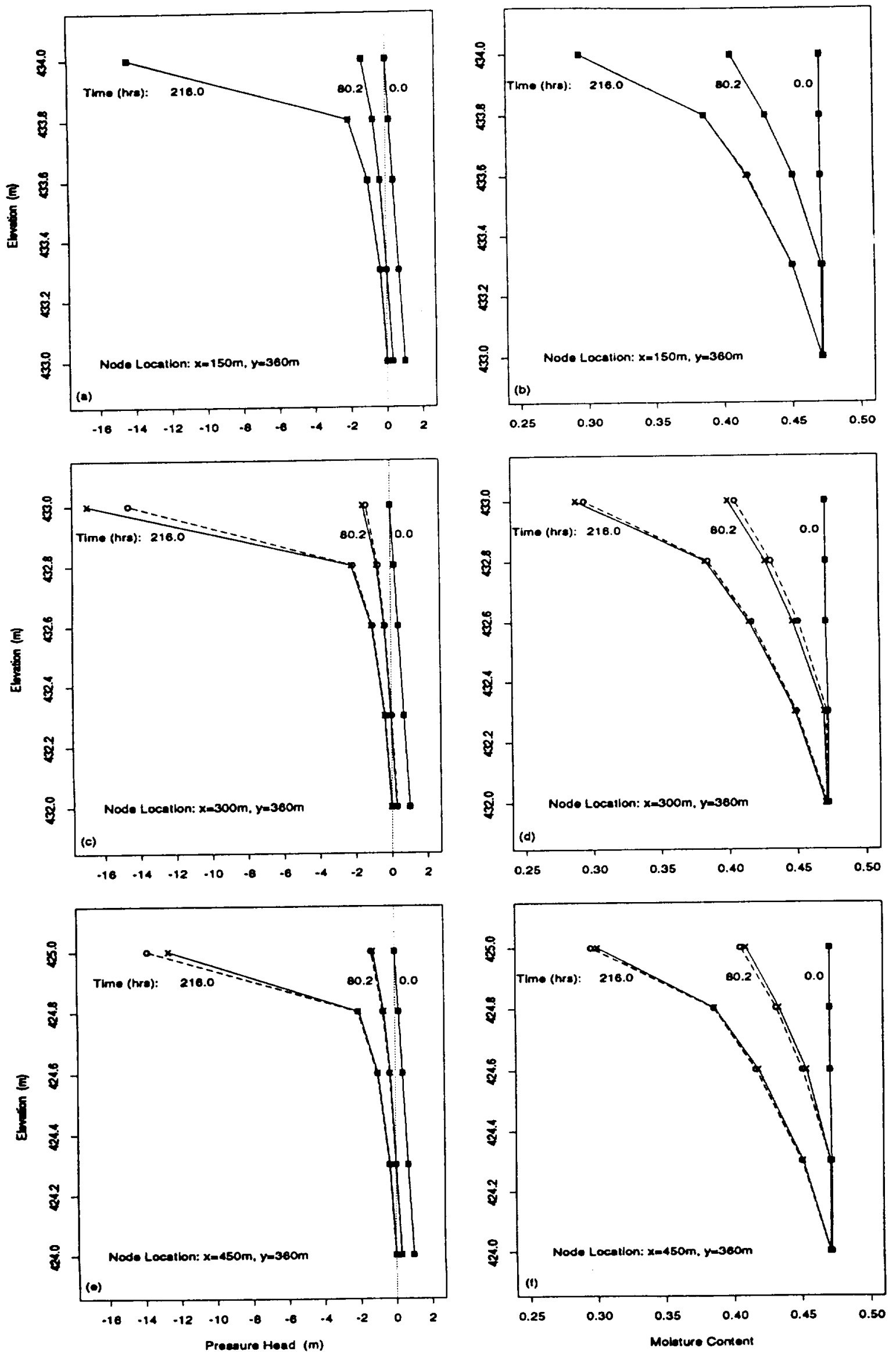

Fig. 10. Vertical profiles for the 9-day evaporation simulation, using $3 \times 3 \mathrm{~m}$ (solid lines) and $30 \times 30 \mathrm{~m}$ (dashed lines) grid discretizations. (Hour 0 is May 29, 1987, 0000 hours.) 

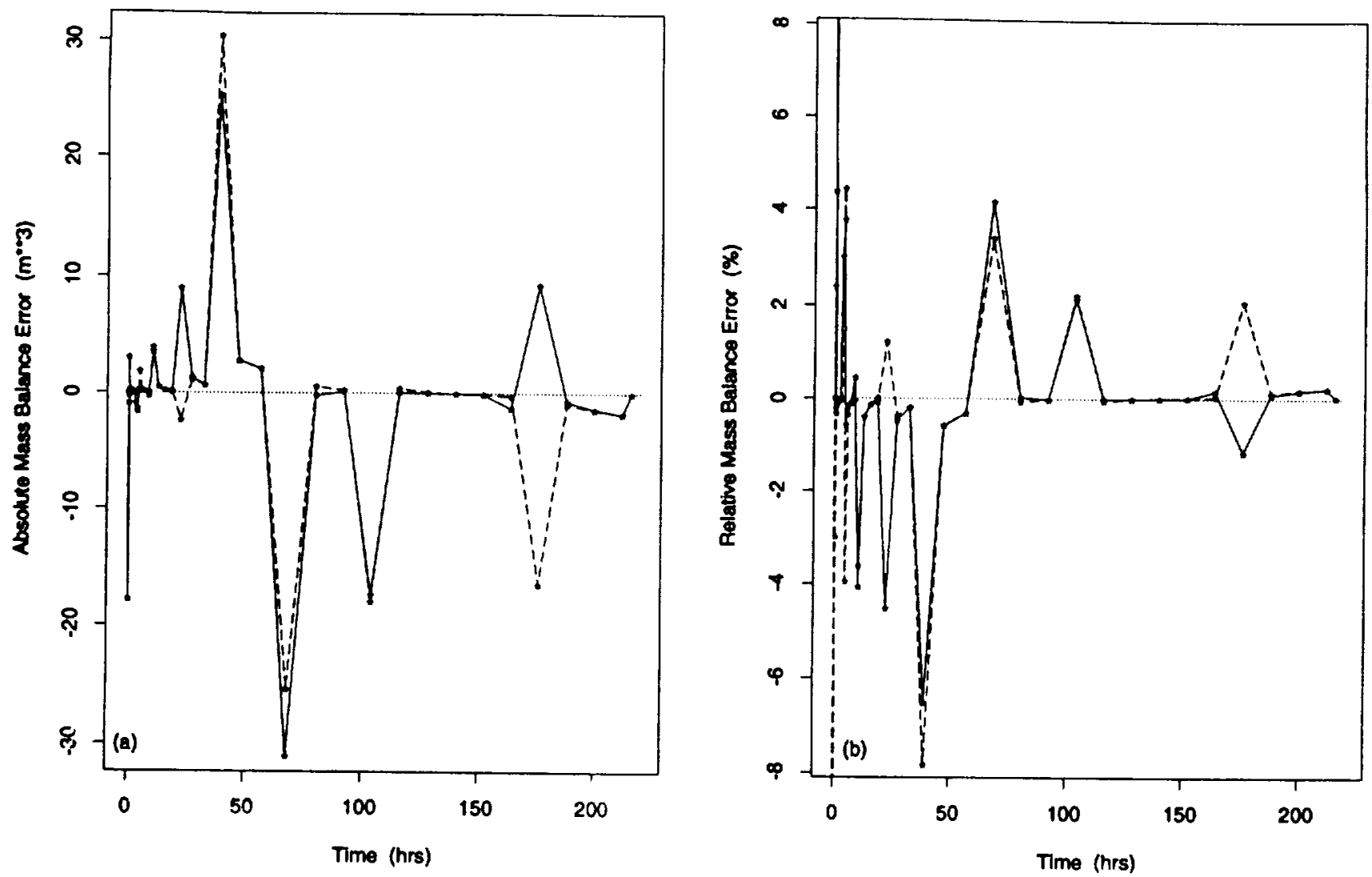

Fig. 11. Mass balance results for the 9-day evaporation simulation, using $3 \times 3 \mathrm{~m}$ (solid lines) and $30 \times 30 \mathrm{~m}$ (dashed lines) grid discretizations. (Hour 0 is May 29, 1987,0000 hours.)

vertical coordinate. The model automatically handles both soil-driven and atmosphere-driven inflows and outfows, and both saturation excess and infiltration excess runoff production. Atmospheric inputs can be spatially and/or temporally variable, and heterogeneities in hydraulic conductivity are also considered. Initial conditions can be generated from elevation and surface conductivity data, and extended van Genuchten equations are used to describe the nonlinear soil hydraulic characteristics. Simplifying assumptions are made to handle flow processes occurring on the catchment surface and in streams. Time stepping is adaptive and based on the convergence behavior of the nonlinear iterative scheme.

The simulation model was applied to subcatchment 1D of the Konza Prairie Research Natural Area in northeastern Kansas. Observation data collected during a 1987 field experiment were used to parameterize and calibrate the model.

In simulations of a 17-day rainfall and interstorm sequence we attempted to match discharge produced by the model with observed streamflow. It was necessary to increase the fitted value of surface saturated conductivity to match the largest of two distinct streamflow events, but with this higher value of surface $K_{s}$ we were unable to match the smaller streamflow peak. Matching both discharge events simultaneously may require information on the spatial variability of saturated conductivity for the ID catchment. The 17-day simulations were performed using both detailed 15 -min rainfall rates and daily-averaged rainfall rates. The detailed rates are necessary if we want to capture the surface saturation response of the catchment during periods of heavy rainfall, but in other respects the use of detailed and averaged rates produced similar hydrologic and numerical results.

Simulations of a 9-day evaporation period were performed using a wide range of spatial grid discretizations in order to study model resolution effects. We obtained satisfactory results using a nonlinear convergence tolerance of $0.05 \mathrm{~m}$ and a grid aspect ratio as large as 150 , indicating that horizontal grid dimensions may not be unreasonably constrained by the typically much smaller vertical length scale of a catchment and by vertical discretization requirements. This is an encouraging result, although tests using heterogeneous parameter distributions and even larger aspect ratios are recommended. Constraints on grid aspect ratios dictated by numerical stability, accuracy, and convergence requirements also need to be investigated.

Much of the work described in this paper is in preliminary stages. In future work we would like to extend the model to handle hysteresis and seepage faces, and improve on the simplifying assumptions used in runoff routing. For a more comprehensive model of catchment scale hydrologic processes, it will be necessary to couple the three-dimensional subsurface flow model to a physically based model of overland flow and channel flow, and to incorporate vegetation, transpiration, macropore flow, and nonisothermal effects. With more detailed and extensive observation data for the ID catchment (e.g., potential evaporation rates, surface soil moisture readings, and surface conductivity measurements) we will be able to run rigorous model assessment tests, including an evaluation of errors in the model formulation. 
It would appear that catchment scale simulations can be feasibly performed using a detailed physically based model. The 9-day evaporation simulation of the $0.24-\mathrm{km}^{2}$ ID catchment required only $67 \mathrm{~s}$ of Cray Y-MP comuter time using a finite element grid of 1570 nodes, and $180 \mathrm{~min}$ of CPU using a 135,355-node mesh. From the fourth, fifth, and sixth columns from the left in Table 4 we estimate the CPU requirement for our simulation model to be $0.001 \mathrm{~s}(2.78 \times$ $10^{-7}$ hours) per time step per node, using a relatively weak convergence tolerance $(t o l=0.05 \mathrm{~m}$ ) and using the ITPACK routine SSORCG vectorized for the Cray Y-MP to solve the linearized system of equations. The U.S. Geological Survey digital elevation data for the entire King's Creek catchment contain 12,913 pixels at $30 \times 30$ meter resolution. The surface area of this catchment is $11.62 \mathrm{~km}^{2}$. A finite element discretization of the Kings Creek catchment using nine vertical layers would yield a 129,130-node mesh. A single 100-time step simulation with this grid would require 3.6 hours of CPU. The mesh for a horizontal discretization of $15 \times 15 \mathrm{~m}$ with four layers vertically would contain approximately 258,260 node, and would require just over 7 hours of CPU, again for a simulation of 100 time steps. Aside from the vectorized SSORCG solver, the numerical model was executed in scalar mode. Significant efficiency gains can be expected from vectorization and parallelization of other components of the model. One possibility would be to assign to each processor of a parallel computer the task of simulating one subcatchment of a large catchment such as Kings Creek.

Acknowledgments. This work was supported in part by the Andrew W. Mellon Foundation and by U.S. NASA grants NAG1392 and NAG5-899. We would also like to acknowledge support from the John von Neumann Center for use of the Cyber 205 (grant NAC 1249) and from the Pittsburgh Supercomputing Center for use of the Cray Y-MP (grant EAR900004P).

\section{REFERENCES}

Ababou, R., D. McLaughlin, L. W. Gelhar, and A. F. B. Tompson, Numerical simulation of three-dimensional saturated flow in randomly heterogeneous porous media, Transp. Porous Media, 4, 549-565, 1989.

Ames, W. F., Numerical Methods for Partial Differential Equations, 2nd ed., Academic, San Diego, Calif., 1977.

Avissar, R., and M. M. Verstraete, The representation of continental surface processes in atmospheric models, Rev. Geophys., 28(1), 35-52, 1990.

Band, L. E., Topographic partition of watersheds with digital elevation models, Water Resour. Res., 22(1), 15-24, 1986.

Bathurst, J. C., Physically-based distributed modelling of an upland catchment using the Systeme Hydrologique Europeen, J. Hydrol., 87, 79-102, 1986.

Beven, K. J., Experiments with a finite element model of hillslope hydrology-The effect of topography, in Surface and Subsurface Hydrology: Proceedings of the Fort Collins Third International Hydrology Symposium, on Theoretical and Applied Hydrology, edited by H. J. Morel-Seytoux, J. D. Salas, T. G. Sanders, and R. E. Smith, pp. 37-51, Water Resources Publications, Fort Collins. Colo., 1977

Beven, K. J., On subsurface stormflow: An analysis of response times, Hydrol. Sci. J., 27(4). 505-521, 1982.

Beven. K. J., Infiltration into a class of vertically non-uniform soils. Hydrol. Sci. J., 29(4), 425-434, 1984.

Beven, K. J., and P. Germann, Macropores and water flow in soils, Water Resour. Res., 18(5), 1311-1325, 1982.

Bhowmik, N. G., Hydrologic research at LTER sites, Eos Trans. $A G U, 68(37), 745,750,756,1987$.

Binley, A. M., J. Elgy, and K. J. Beven, A physically based model of heterogeneous hillslopes, 1, Runoff production, Water Resour. Res., 25(6), 1219-1226, 1989a.

Binley, A. M.. K. J. Beven, and J. Elgy, A physically based model of heterogeneous hillslopes, 2, Effective hydraulic conductivities, Water Resour. Res., 25(6), 1227-1234, $1989 b$.

Blain, C. A., Development of a physically based numerical soit moisture flow model which has applications to the soil matrix and macropore domains, M.S. thesis. Dep. of Civ. Eng. and Oper. Res., Princeton Univ., Princeton, N. J., 1989.

Broadbridge, $P$., and 1 . White, Time to ponding: Comparison of analytic, quasi-analytic, and approximate predictions, Water Resour. Res., 23(12), 2302-2310, 1987.

Calver, A., and W. L. Wood, On the discretization and costeffectiveness of a finite element solution for hillslope subsurface flow, J. Hydrol., 110, 165-179, 1989.

Cooley, R. L., Some new procedures for numerical solution of variably saturated flow problems. Water Resour. Res.. 19(5). $1271-1285,1983$.

de Vries, D. A., Simultaneous transfer of heat and moisture in porous media, Eos Trans. AGU, 39(5), 909-916, 1958.

Dunne. T., and R. D. Black. Partial area contributions to storm runoff in a small New England watershed, Water Resour. Res., 6(5), 1296-1311, 1970.

Eagleson, P. S., Dynamic Hydrology, McGraw-Hill, New York, 1970.

Eagleson, P. S., Climate, soil, and vegetation, 1, Introduction to water balance dynamics, Water Resour. Res., 14(5), 705-712. 1978.

Eagleson. P. S., The annual water balance, J. Hydraul. Div. Am. Soc. Civ. Eng., 105(HY8), 923-941, 1979.

Engman, E. T., G. Angus, and W. P. Kustas, Relationships between the hydrologic balance of a small watershed and remotely sensed soil moisture, in Remote Sensing and Large-Scale Global Processes: Proceedings of the IAHS Third International Assembly, edited by A. Rango, IAHS Publ. 186, 75-84, 1989.

Federer, C. A., A soil-plant-atmosphere model for transpiration and availability of soil water, Water Resour. Res., 15(3), 555-562, 1979.

Freeze, R. A., Three-dimensional, transient, saturated-unsaturated flow in a groundwater basin, Water Resour. Res., 7(2), 347-366, 1971 .

Freeze, R. A., Role of subsurface flow in generating surface runoff, 1. Base flow contributions to channel flow, Water Resour. Res.. 8(3), 609-623, $1972 a$.

Freeze, R. A., Role of subsurface flow in generating surface runoff, 2. Upstream source areas, Water Resour. Res., 8(5), 1272-1283, $1972 b$.

Freeze, R. A., Streamflow generation, Rev. Geophys., 12(4), 627647, 1974.

Freeze, R. A., and J. A. Cherry, Groundwater, Prentice-Hall, Englewood Cliffs, N. J., 1979.

Gan, T. Y., and S. J. Burges, An assessment of a conceptual rainfall-runoff model's ability to represent the dynamics of small hypothetical catchments, 1 , Models, model properties, and experimental design, Water Resour. Res., 26(7), 1595-1604, 1990a.

Gan, T. Y., and S. J. Burges, An assessment of a conceptual rainfall-runoff model's ability to represent the dynamics of small hypothetical catchments, 2, Hydrologic responses for normal and extreme rainfall, Water Resour. Kes., 26(7), 1605-1620, 1990 b.

Germann, P. F., Preferential flow and the generation of runoff, 1 , Boundary layer flow theory, Water Resour. Res., 26(12), 3055$3063,1990$.

Goodrich, D. C., and D. A. Woolhiser, Catchment hydrology, U.S. Natl. Rep. Int. Union Geod. Geophys. 1987-1990, Rev. Geophys., 29(Suppl.), 202-209, 1991.

Govindaraju, R. S., and M. L. Kavvas, Dynamics of moving boundary overland flows over infiltrating surfaces at hillslopes, Water Resour. Res., 27(8), 1885-1898, 1991.

Hillel, D., Fundamentals of Soil Physics, Academic, San Diego, Calif. 1980a.

Hillel, D., Applicasioms of Soil Physics, Academic, San Diego. Calif., $1980 b$.

Huyakorn, P. S., and G. F. Pinder, Compurational Methods in Subsurface Flow, Academic, San Diego, Calif., 1983.

Huyakorn, P. S., E. P. Springer, V. Guvanasen, and T. D. Wadsworth, A three-dimensional finite-element model for simu- 
lating water flow in variably saturated porus media, Water Re. sour. Res., 22(13), 1790-1808, 1986.

James, L. D., and S. J. Burges, Selection, calibration, and testing of hydrologic models, in Hydrologic Modeling of Small Watersheds, edited by C. T. Haan, H. P. Johnson, and D. L. Brakensiek, pp. 437-472. American Society of Agricultural Engineers. St. Joseph. Mich., 1982.

Kincaid, D. R., J. R. Respess, D. M. Young, and R. G. Grimes, ITPACK 2C: A FORTRAN package for solving large sparse linear systems by adaptive accelerated iterative methods, $A C M$ Trans. Math. Software, 8(3), 302-322, 1982.

Kool, J. B., and J. C. Parker, Development and evaluation of closed-form expressions for hysteretic soil hydraulic properties, Water Resour. Res., 23(1), 105-114, 1987.

Loague, K., R-5 revisited, 2, Reevaluation of a quasi-physically based rainfall-runoff model with supplemental information, Water Resour. Res., 26(5), 973-987, 1990.

Loague, K. M., and R. A. Freeze, A comparison of rainfall-runoff modeling techniques on small upland catchments, Water Resour. Res., 2I(2), 229-248, 1985.

McDonnell, J. J., A rationale for old water discharge through macropores in a steep, humid catchment, Water Resour. Res., 26(11), 2821-2832, 1990.

Milly, P. C. D., Moisture and heat transport in hysteretic, inhomogeneous porous media: A matric head-based formulation and a numerical model, Wuter Resour. Res., 18(3), 489-498, 1982.

Mualem. Y., A conceptal model of hysteresis, Water Resour. Res., 10(3), $514-520,1974$

Neuman, S. P.. Saturated-unsaturated seepage by finite elements, $J$. Hy'draul. Div. Am. Soc. Civ. Eng., 99, 2233-2250, 1973.

Paniconi, C., Hydrologic processes in variably saturated porous media: Analysis of numerical methods for solving the nonlinear Richards equation, and application to catchment scale simulations, Ph.D. dissertation, Dep. of Civ. Eng. and Oper. Res., Princeton Univ., Princeton, N. J., 1991.

Paniconi, C., A. A. Aldama, and E. F. Wood, Numerical evaluation of iterative and noniterative methods for the solution of the nonlinear Richards equation, Water Resour. Res., 27(6), 11471163. 1991.

Parlange, J.-Y., Capillary hysteresis and the relationship between drying and wetting curves, Water Resour. Res., 12(2), 224-228, 1976.

Pearce, A. J.. Streamfiow generation processes: An austral view, Water Resour. Res., 26(12), 3037-3047, 1990.

Philip, J. R., and D. A. de Vries, Moisture movement in porous materials under temperature gradients, Eos Trans. AGU, 38(2), 222-232, 1957.
Rawls, W. J., D. L. Brakensiek, and K. E Saxton, Estimation of soil water properties, Trans. ASAE, 2S(S), 1316-1320, 1328, 1982.

Reeves, M., and E. E. Miller, Estimating infiltration for erratic rainfall, Water Resour. Res., I/(1), 102-110, 1975.

Sellers, P. J., F. G. Hall. D. E. Strebel, E. T. Kanemasu, R. D Kelly, B. L. Blad, B. J. Markham, and J. R. Wang. Experiment design and operations, in Symposium on FIFE, pp. 1-5, American Meteorological Society, Boston, Mass., 1990.

Shamsai, A., and T. N. Narasimhan. A numerical investigation of free surface-seepage face relationship under steady state flow conditions, Water Resour. Res., 27(3), 409-421, 1991.

Sivapalan, M., K. J. Beven, and E. F. Wood, On hydrologic similarity, 2, A scaled model of storm runoff production, Water Resour. Res., 23(12), 2266-2278, 1987.

Sloan, P. G., and I. G. Moore, Modeling subsurface stormflow on steeply sloping forested watersheds, Water Resour. Res. 20(12), 1815-1822, 1984.

Smith, R. E., and R. H. B. Hebbert, Mathematical simulation of interdependent surface and subsurface hydrologic processes, $\mathrm{Wa}$ ter Resour. Res., 19(4), 987-1001, 1983

Sposito, G., The "physics" of soil water physics, Water Resour. Res., 22(9), 83S-88S, 1986.

Stagnitti, F., M. B. Parlange, T. S. Steenhuis, and J.-Y. Parlange, Drainage from a uniform soil layer on a hillslope, Water Resour. Res., 22(5), 631-634, 1986.

Troch, P. A., M. Mancini, C. Paniconi, and E. F. Wood, Evaluation of a distributed catchment scale water balance model, Water Resour. Res., in press, 1993.

van Genuchten, M. T., and D. R. Nielsen, On describing and predicting the hydraulic properties of unsaturated soils, $A n n$. Geophys., 3(5), 615-628, 1985.

Wilcox, B. P., W. J. Rawls, D. L. Brakensiek, and J. R. Wright, Predicting runoff from rangeland catchments: A comparison of two models, Water Resour. Res., 26(10), 2401-2410, 1990.

Wood, E. F., M. Sivapalan, K. J. Beven, and L. E. Band, Effects of spatial variability and scale with implications to hydrologic mod. eling. J. Hydrol., 102, 29-47, 1988.

C. Paniconi, CRS4, Via Nazario Sauro 10, I-09123 Cagliari, Italy. E. F. Wood, Water Resources Program, Department of Civil Engineering and Operations Research, Princeton University, Princeton, NJ 08544 .

(Received January 30, 1992;

revised September 15, 1992 . accepted September 28, 1992.) 

